Preprints of the

Max Planck Institute for

Research on Collective Goods

Bonn 2009/6

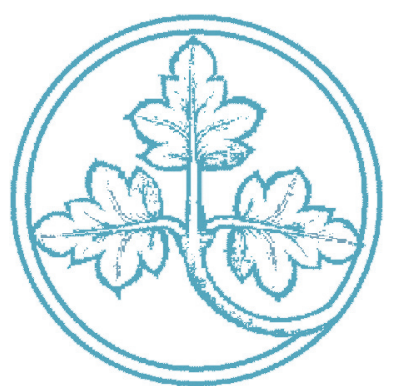

Strategic Information

Disclosure and Competition for an Imperfectly Protected Innovation

Jos Jansen

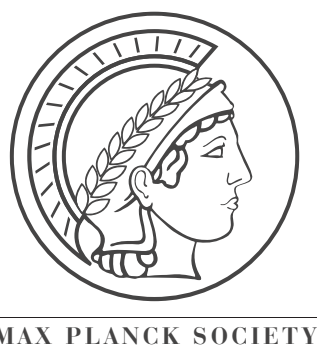




\section{Strategic Information Disclosure and Competition for an Imperfectly Protected Innovation}

Jos Jansen

February 2009 


\title{
Strategic Information Disclosure and Competition for an Imperfectly Protected Innovation*
}

\author{
Jos Jansen \\ Max Planck Institute for Research on Collective Goods ${ }^{\dagger}$ \\ February 2009
}

\begin{abstract}
The imperfect appropriability of revenues from innovation affects the incentives of firms to invest, and to disclose information about their innovative productivity. It creates a free-rider effect in the competition for the innovation that countervails the familiar business-stealing effect. Moreover, it affects the disclosure incentives such that full disclosure emerges for extreme revenue spillovers (e.g., full protection and no protection of intellectual property), but either partial disclosure or full concealment emerges for intermediate spillovers. I analyze the implications of imperfect appropriability and strategic disclosure for the firms' profits and the probability of innovation.
\end{abstract}

Keywords: R\&D competition, innovation, spillovers, information disclosure, strategic substitutes, free-rider effect, externality

JEL Codes: D82, D83, L23, O31, O32

${ }^{*}$ This paper supersedes the unpublished papers Jansen (2001) and Jansen (2004). I thank two anonymous referees, Patrick Bolton, Eric van Damme, Yeon-Koo Che, Simona Fabrizi, Guido Friebel, Sanjeev Goyal, Martin Hellwig, Bruno Jullien, Johan Lagerlöf, Tor Jakob Klette, Nicolas Melissas, Giuseppe Moscarini, Rick van der Ploeg, Luca Rigotti, Armin Schmutzler, Yossi Spiegel, and Dolf Talman for helpful comments and discussions. I also thank participants of seminars at CentER, Free University Berlin, University of Zürich, WZB, EARIE conference (Copenhagen), Econometric Society World Congress (Seattle), CEPR workshop on "Product Markets, Financial Markets and the Pace of Innovation in Europe" (Brussels), EEA Congress (Lausanne), 10th WZB Conference on Industrial Organization (Berlin), Workshop on Licensing (Milan), and IUI/CEPR conference on "Innovation, Ownership and Competition" (Vaxholm) for comments, and Brian Cooper for careful proof-reading. The support of MPSE (Toulouse), Princeton University, Tilburg University, WZB (Berlin), EUI (Florence), the ENTER exchange program, and Netherlands Organization for Scientific Research (NWO) grant R 46-362 are gratefully acknowledged. All errors are mine.

†Address: Kurt-Schumacher-Str. 10, D-53113 Bonn, Germany; e-mail <jansen@coll.mpg.de> 


\section{Introduction}

Firms that invest in research and development $(\mathrm{R} \& \mathrm{D})$ manage their rivals' beliefs by revealing and concealing intermediate information. Innovative firms employ a variety of strategies to inform the market about their capability to develop new technologies. In some industries firms make announcements about their upcoming innovations. Firms reveal intermediate successes, give predictions about the date at which the new product will be launched, or make other announcements related to their capability of producing an innovation. Announcements by biotechnology and software firms about intermediate successes are common practice. In other industries firms work in complete secrecy. Many e-commerce firms go in so-called "stealth mode" to work on new products. The firms do not make any announcements about their innovative capabilities or upcoming products until the innovation is made. This paper attempts to explain these information revelation strategies. In particular, I study the role that the appropriability of an innovator's revenue plays in explaining which information revelation strategy a firm uses.

In this paper I analyze incentives for the strategic disclosure of a firm's cost of investment. An important feature of the model is that firms apply similar R\&D technologies to obtain their innovation, i.e., the firms' costs of investment are (perfectly) positively correlated. The release of good news by one firm makes its rivals more optimistic about their own opportunities in the R\&D competition, which gives them a greater incentive to invest. Illustrations of this effect can be found in the races for cold superconductivity and biotechnology. ${ }^{1}$ A second feature of the model is that information revealed by firms is verifiable. Firms disclose their information through, e.g., scientific journals or presentations in scientific conferences and trade shows. ${ }^{2}$

The incentive to invest in $\mathrm{R} \& \mathrm{D}$ is determined by the trade-off between two effects. On the one hand, there is the well-known business-stealing effect. If firms compete for an innovation where the winner takes all, and R\&D investments are strategic substitutes, then each firm has an incentive to overinvest in R\&D. On the other hand, there is a free-rider effect if the winner of a $R \& D$ competition cannot appropriate the

\footnotetext{
${ }^{1}$ Choi (1991) gives an example of the 1986 breakthrough in cold superconductivity by IBM. IBM's intermediate success made other firms more optimistic about the feasibility of cold superconductivity, and increased the investment intensity in the race for cold superconductivity. In the biotechnology industry, Austen (1993) observes that an intermediate success by one biotechnology firm leads to an increase in valuation of other firms in the industry.

${ }^{2}$ For example, in the race for cold superconductivity the IBM researchers published their breakthrough in a scientific journal (Choi, 1991). In other instances, the information transmitted by firms may not be verifiable. Section 6 briefly discusses the incentives to misrepresent cost information.
} 
full revenue of his innovation, since part of the innovation's revenue spills over to the loser. $^{3}$ The free-rider effect reduces the incentives to invest in R\&D. For example, firms underinvest in $\mathrm{R} \& \mathrm{D}$, if intellectual property rights are absent, and the winner and loser of the R\&D competition obtain an equal share of the innovation's revenue. A reduction of appropriability initially increases the expected profits, since free-riding reduces $R \& D$ overinvestments, but subsequently it decreases expected profits, since it turns overinvestments into underinvestments. Free-riding makes it less likely that an innovation emerges.

The business-stealing effect and the free-rider effect also give conflicting incentives to strategically disclose information about the cost of investment. First, if the business-stealing effect dominates, then a firm has an incentive to discourage its rival from investing. Therefore, a firm has an incentive to withhold good news and disclose only bad news about the cost of investment. A skeptical rival infers that a concealing firm received good news. The rival's perfect inference eliminates the firm's incentive to conceal information, and full disclosure emerges in equilibrium. Second, if the free-rider effect dominates, then the disclosure incentive is reversed. A firm discloses good news and conceals bad news to encourage investments by its rival, and free-ride on the revenue generated by them. Now a rival with skeptical beliefs infers that a concealing firm has bad news, and again full disclosure results. In short, for extreme protection parameters the "unraveling result" emerges (Grossman, 1981, Milgrom, 1981, and Okuno-Fujiwara et al., 1990).

Whereas the disclosure incentives are clear for extreme appropriability values (i.e., values corresponding to full protection or no protection of intellectual property rights), there is a more subtle trade-off between the two effects for intermediate spillover values. In those cases countervailing incentives emerge (e.g., Lewis and Sappington, 1989). For a firm with good news the business-stealing effect dominates, which gives this firm the incentive to discourage its rival by concealing the good news. Conversely, for a firm with bad news the free-rider effect dominates, which gives such a firm an incentive to encourage its rival by concealing the bad news. That is, for intermediate spillover values both firm types have an incentive to conceal information, and can therefore do so in a credible way.

Information disclosure affects different firms in different ways. A receiver of information earns on average a higher profit after disclosure, since the information enables

\footnotetext{
${ }^{3}$ In practice, it is not feasible or desirable to protect an innovation perfectly from imitation (e.g., see Denicolò, 1996). In such cases the "winner-take-all" prize structure does not emerge.
} 
him to adjust his investment to the actual cost of investment. By contrast, a sender prefers to precommit to secrecy, since this avoids investment adjustments by the receiver, and keeps the correlation between the firms' investments low. ${ }^{4}$

The fact that the disclosure strategy changes in the spillover size has implications for the profits of firms and the probability of innovation. A spillover change may also affect the investments and profits indirectly through changes in the disclosure strategy and beliefs. This indirect effect is absent in, e.g., De Fraja (1993), Denicolò (1996), Katsoulacos and Ulph (1998), Kamien and Zang (2000), Moldovanu and Sela (2001), Gersbach and Schmutzler (2003), and Fosfuri and Rønde (2004), who analyze the effects of spillovers in settings with complete information.

The indirect effect reinforces the direct effect for a sender. That is, both the investment incentives and disclosure incentives are optimal for intermediate degrees of appropriability, while they are both suboptimal otherwise. By contrast, for an information receiver, the indirect effect conflicts the direct effect. The investment incentives are optimal, while the disclosure incentives are suboptimal for intermediate appropriability values, and vice versa for extreme values. In that case, strategic disclosure may reverse the effect of knowledge appropriability on the receiver's profit. A similar trade-off emerges in the analysis of the probability of innovation.

There exists some literature on the effects of asymmetric information and information disclosure among innovative firms, e.g., see Bhattacharya and Ritter (1983), Bhattacharya et al. (1990, 1992), d'Aspremont et al. (1998, 2000), Rosenkranz (2001), Anton and Yao (2003, 2004), Bhattacharya and Guriev (2006), and Gill (2008). However, in these papers the free-rider effect is absent. Information is substantive in these papers, in the sense that disclosure directly improves the receiver's productivity. ${ }^{5}$ By contrast, in the present paper firms choose disclosure strategies exclusively to affect the beliefs of a rival firm without any direct productivity effect.

The paper is organized as follows. The next section describes the model. Section 3 characterizes the equilibrium $R \& D$ investments and profits for given disclosure rules. Section 4 analyzes the disclosure incentives. Section 5 analyzes some implications, by characterizing the overall expected profits of the firms, and the probability of innovation. Section 6 briefly discusses some extensions to the basic model, and concludes the paper. The proofs of the main results are relegated to the Appendix.

\footnotetext{
${ }^{4}$ For recent surveys on information sharing in oligopoly, see, e.g., Raith (1996), and Vives (1999).

${ }^{5}$ For example, a firm with an inferior technology can reduce its cost by signing a licensing contract (Bhattacharya et al., 1990, 1992, d'Aspremont et al., 1998, 2000, and Bhattacharya and Guriev, 2006), or infringing an imperfect patent (Anton and Yao, 2003, 2004).
} 


\section{The Model}

Consider two risk-neutral firms, firm $R$ and $S$, that compete for an innovation. The two firms have identical costs of investments, i.e., costs are perfectly positively correlated. Initially, firms do not know their investment cost parameter, $\theta$. This cost parameter is either low, $\theta=\underline{\theta}$, with probability $p$, or high, $\theta=\bar{\theta}$, with probability $1-p$, where $0 \leq \underline{\theta}<\bar{\theta}$ and $0<p<1$. Firm $S$, the sender, learns the cost of investment, while firm $R$, the receiver, does not learn. ${ }^{6}$

In stage 1 firm $S$ chooses its disclosure rule. I assume that the cost information is costlessly verifiable. Therefore, the only choice that the firm has, is to either truthfully reveal its information or conceal it (i.e., send the uninformative message $\varnothing$ ). That is, firm $S$ chooses disclosure rule $\boldsymbol{\mu} \equiv(\mu(\underline{\theta}), \mu(\bar{\theta}))$, where $\mu(\theta)$ is the probability with which firm $S$ discloses cost parameter $\theta$, and $1-\mu(\theta)$ is the probability with which it conceals $\theta$, with $0 \leq \mu(\theta) \leq 1$ for $\theta \in\{\underline{\theta}, \bar{\theta}\}$. Firm $R$ receives the realization of rule $\boldsymbol{\mu}$, i.e., the message $m \in\{\theta, \varnothing\}$, from firm $S$.

In stage 2 , the firms simultaneously choose their R\&D investments. If firm $i$ spends $x_{i} \in[0,1]$, its probability of obtaining an innovation is $x_{i}$. In order to keep the model manageable, I assume that firm $i$ 's cost of investment is $c\left(x_{i} ; \theta\right)=\theta x_{i}+\frac{1}{2} \lambda x_{i}^{2}$, for $\theta \in\{\underline{\theta}, \bar{\theta}\}$ and $i \in\{R, S\} .{ }^{7}$ Parameter $\lambda>0$ yields decreasing returns to investment. A higher $\lambda$ makes a firm's marginal cost function steeper in the firm's investment.

There are three possible outcomes for the firms. In the first outcome, only one firm develops the innovation. I assume that the loser of the R\&D competition receives share $\sigma$ of the winner's prize $V$. Hence, the winner receives $(1-\sigma) V$, while the loser receives $\sigma V$, with $0 \leq \sigma \leq \frac{1}{2} \cdot{ }^{8}$ For $\sigma=0$, a winner-take-all prize structure emerges, while for $\sigma=\frac{1}{2}$ firms share the prize equally. In the second outcome, both firms successfully develop the innovation, and each receives prize $V / 2 .{ }^{9}$ In the third outcome, neither firm obtains the innovation, and neither firm receives revenues. I impose the following

\footnotetext{
${ }^{6}$ Jansen (2004) analyzes the model where both firms receive imperfect cost signals. This model of two-sided asymmetric information gives essentially the same economic insights.

${ }^{7}$ Jansen (2001) assumes the cost function $c\left(x_{i} ; \theta\right)=\frac{1}{2} \theta x_{i}^{2}$ with $\theta \in\{\underline{\theta}, \bar{\theta}\}$. This assumption gives qualitatively similar results, and is equivalent to assuming that the firms do not know the size of prize $V$. The current cost structure is easier to analyze.

${ }^{8} \mathrm{~A}$ setting in which the total prize remains constant, and a fixed share of the winner's prize spills over to the loser (i.e., no dissipation of rents) keeps the model tractable.

${ }^{9}$ In Jansen (2001) I adopt a more general prize structure, where each firm obtains prize $T$, with $0 \leq T \leq \frac{1}{2} V$, if both firms are successful. The main qualitative results of the general model do not differ from those in the present paper.
} 
regularity condition to obtain interior solutions for firms' R\&D investments:

$$
3 \bar{\theta}-\underline{\theta} \leq V<\lambda
$$

The second condition $(\lambda>V)$ is sufficient to make firms choose investment levels below 1 , while the additional condition $(V \geq 3 \bar{\theta}-\underline{\theta})$ is sufficient for firms to choose non-negative investment levels.

Given R\&D investments $\mathbf{x} \equiv\left(x_{i}, x_{j}\right)$, firm $i$ 's expected second-stage profits are (for $i, j \in\{R, S\}$ and $i \neq j$ ):

$$
\begin{aligned}
\pi_{i}(\mathbf{x} ; \theta, \sigma) & =x_{i} x_{j} \frac{1}{2} V+x_{i}\left(1-x_{j}\right)(1-\sigma) V+\left(1-x_{i}\right) x_{j} \sigma V-\theta x_{i}-\frac{1}{2} \lambda x_{i}^{2} \\
& =x_{i}\left((1-\sigma) V-\theta-\frac{1}{2} V x_{j}\right)-\frac{1}{2} \lambda x_{i}^{2}+\sigma V x_{j}
\end{aligned}
$$

The model's prize structure is such that the firms' profits are submodular in $\mathbf{x} .{ }^{10}$ This yields a business-stealing motive. The positive spillover $\sigma$ introduces free-rider motives. The model captures situations where these two motives are present.

The model's prize structure is consistent with the following examples of structural form models. First, the prizes can emerge from R\&D worker mobility in a model of trade secrecy (e.g., Gersbach and Schmutzler, 2003, and Fosfuri and Rønde, 2004). Suppose the innovation is an essential input for the production technologies of firms $R$ and $S$, i.e. no production is possible in the absence of the innovation. A firm's R\&D worker moves to the firm's rival with probability $2 \sigma$, and the worker stays with the firm with probability $1-2 \sigma \cdot{ }^{11}$ After a worker moves from a successful firm, both firms have the innovation. If both firms have the innovation, then each firm earns the duopoly profit $V / 2$, while if only one firm has the innovation, then it earns the monopoly profit $V$. Hence, if only one firm innovates, the winner's and loser's expected prizes equal:

$$
\begin{aligned}
\pi^{W} & =(1-2 \sigma) V+2 \sigma \cdot V / 2=(1-\sigma) V, \text { and } \\
\pi^{L} & =(1-2 \sigma) 0+2 \sigma \cdot V / 2=\sigma V
\end{aligned}
$$

respectively. For example, if there is no risk of worker migration, the winner-take-all payoffs emerge, and with certain labor migration the equal-sharing payoffs apply.

\footnotetext{
${ }^{10}$ In this model with spillovers in the product market the investments are always strategic substitutes. By contrast, in models with spillovers in the investment stage (e.g., Kamien and Zang, 2000) the investments may become strategic complements for strong spillovers.

${ }^{11}$ For example, the firms can influence the risk by choosing the their locations (e.g., the distance from each other, or the area's enforcement of post-employment convenants to compete).
} 
Second, the prize structure can be generated by a model of probabilistic patents (e.g., Anton and Yao, 2004). Again, suppose that the innovation is essential for profitable production by a firm. The goods are differentiated, and each product generates a profit of $V / 2$. If only one firm innovates, it receives a patent which is valid (invalid) with probability $1-2 \sigma$ (resp. $2 \sigma$ ). If both firms are successful, the patent is randomly assigned to one of the firms with equal probability. The holder of a valid patent extracts the total industry profit $V$ (i.e., the profit in its own market, $V / 2$, and the rival's profit, $V / 2$ ) through a fixed licensing fee. ${ }^{12}$ An invalid patent gives each firm the profit from its own good, i.e., $V / 2$. Hence, a winner's and loser's expected prizes equal (2.3) and (2.4), respectively. For example, the winner-take-all payoffs correspond to a patent with certain validity, while the equal-sharing payoffs correspond to an invalid patent. ${ }^{13}$

I solve the game backwards, and focus on perfect Bayesian equilibria.

\section{Equilibrium R\&D}

In this section I characterize the equilibrium $R \& D$ investments and profits for any exogenously given information disclosure rule $(\mu(\underline{\theta}), \mu(\bar{\theta}))$.

\subsection{Investments}

At the time that firms choose their R\&D investments they have the following information. Firm $S$ received its cost information $\theta \in\{\underline{\theta}, \bar{\theta}\}$, and it sent message $m \in\{\theta, \varnothing\}$ to its rival. The disclosure rule $(\mu(\underline{\theta}), \mu(\bar{\theta}))$ determines the probability with which firm $S$ sends the messages $\underline{\theta}$ and $\bar{\theta}$, respectively. Given message $m$ firm $R$ assigns posterior belief $P(m)$ to having a low cost of investment $(\theta=\underline{\theta})$, i.e., firm $R$ 's posterior

\footnotetext{
${ }^{12}$ Notice that the goods $R$ and $S$ need to be sufficiently weak substitutes. As long as the singleproduct monopoly profit is lower than the sum of duopoly profits, a patent holder prefers to license its technology to its rival against a fixed fee. For example, identical Cournot duopolists with linear inverse demand functions, $P_{i}\left(q_{i}, q_{j}\right)=a-q_{i}-b q_{j}$, have an incentive to license for all $b<2(\sqrt{2}-1)$.

${ }^{13}$ Alternatively, the spillover can be related to the length of a valid patent, $T$ (Denicolò, 1996). The patent holder extracts the total industry profit flow during the patent life. After the patent expires, each firm receives the profit flow from its own good. Using discount factor $r$, define $\sigma \equiv \frac{1}{2} e^{-r T}$, and define the present value of an eternal profit flow from good $i$ as $V / 2$ for $i \in\{R, S\}$. Then the present values of the winner's and loser's profits are (2.3) and (2.4), respectively. For example, the winner-take-all payoffs correspond to an infinite patent length (i.e., $\lim _{T \rightarrow \infty} \sigma=0$ ), while the equal-sharing payoffs correspond to a patent of zero length (i.e., $\lim _{T \rightarrow 0} \sigma=\frac{1}{2}$ ).
} 
expected cost of investment equals $E\{\theta \mid m\}=P(m) \underline{\theta}+(1-P(m)) \bar{\theta}$, where:

$$
P(m) \equiv\left\{\begin{array}{l}
1, \text { if } m=\underline{\bar{\theta}} \\
0, \text { if } m=\bar{\theta}, \\
\frac{p[1-\mu(\theta)]}{1-E\{\mu(\theta)\}}, \text { if } m=\varnothing .
\end{array}\right.
$$

Firm $S$ receives good news and conceals it with probability $p[1-\mu(\underline{\theta})]$. The probability with which firm $S$ conceals information is $1-E\{\mu(\theta)\}$. If the probability of disclosing a good signal increases, it becomes more likely that a concealing firm has a bad signal, and therefore $\partial P(\varnothing) / \partial \mu(\underline{\theta})<0$. Naturally, a marginal increase in the probability of disclosing a bad signal has the opposite effect, i.e., $\partial P(\varnothing) / \partial \mu(\bar{\theta})>0$.

Profit maximization, given these beliefs, yields the following first order conditions:

$$
\begin{aligned}
\lambda x_{R}^{*}(m) & =(1-\sigma) V-E\{\theta \mid m\}-E\left\{x_{S}^{*}(\theta ; m) \mid m\right\} V / 2, \\
\lambda x_{S}^{*}(\theta ; m) & =(1-\sigma) V-\theta-x_{R}^{*}(m) V / 2 .
\end{aligned}
$$

Notice that a firm's best response is decreasing in its rival's expected investment, i.e., the firms' investments are strategic substitutes. The equilibrium investments $x_{R}^{*}(m)$ and $x_{S}^{*}(\theta ; m)$ are the solution to the system of first-order conditions (3.2)-(3.3). Under condition (2.1) the solution always exists and is unique (see, e.g., Vives, 1999). The properties of these investments are summarized in the following lemma.

Lemma 1 For any exogenously given disclosure rule $(\mu(\underline{\theta}), \mu(\bar{\theta}))$, the equilibrium RESD incentives are such that: (a) investments are decreasing in the spillover $\sigma$; (b) firm $R$ 's investments are ranked as $x_{R}^{*}(\underline{\theta}) \geq x_{R}^{*}(\varnothing) \geq x_{R}^{*}(\bar{\theta})$, and firm $S$ 's investments are ranked as $x_{S}^{*}(\underline{\theta} ; \varnothing) \geq x_{S}^{*}(\underline{\theta} ; \underline{\theta})>x_{S}^{*}(\bar{\theta} ; \bar{\theta}) \geq x_{S}^{*}(\bar{\theta} ; \varnothing) ;$ (c) the investment of firm $R(S)$ with an uninformative message is non-increasing (non-decreasing) in disclosure probability $\mu(\underline{\theta})$; a reduction of $\mu(\bar{\theta})$ has similar effects; (d) the ex ante expected investment is independent of the disclosure rule, and identical for both firms.

One immediate observation from the inspection of (3.2) and (3.3) is that an increase of the spillover $\sigma$ shifts both firms' best response curves inward. A greater spillover yields greater free-rider incentives. Consequently, a firm's equilibrium R\&D investment is decreasing in the spillover, i.e., $\partial x_{i}^{*} / \partial \sigma<0$ for $i \in\{R, S\}$.

Firm $R$ 's investment incentive depends as follows on the firm's beliefs. On the one hand, a firm with a higher posterior probability $P(m)$ is more optimistic about its costs of investment. But, on the other hand, a firm with a high posterior probability $P(m)$ expects fiercer competition than a firm with a lower posterior belief. Since the 
direct cost effect outweighs the indirect competition effect, a more optimistic firm invests more than a pessimistic firm, i.e., $x_{R}^{*}(\bar{\theta}) \leq x_{R}^{*}(\varnothing) \leq x_{R}^{*}(\underline{\theta})$, as stated in part (b) of the lemma. Moreover, the equilibrium investment of firm $R$ with message $\varnothing$ is increasing in posterior probability $P(\varnothing)$, i.e., $\partial x_{R}^{*}(\varnothing) / \partial P(\varnothing)>0 .{ }^{14}$

Firm $S$ chooses the best response strategy to firm $R$ 's investment levels. Analogous to the observation on firm $R$ 's investment incentives, firm $S$ with good news has a greater incentive to invest in R\&D than firm $S$ with bad news, i.e., $x_{S}^{*}(\underline{\theta} ; m)>$ $x_{S}^{*}\left(\bar{\theta} ; m^{\prime}\right)$ for any feasible messages $m$ and $m^{\prime}$. The effect of disclosure on the investment incentive of firm $S$ depends on the effect of disclosure on firm $R$ 's beliefs. Firm $R$ is more pessimistic about the cost of investment after concealment of good news, and invests less, than after disclosure. Consequently, firm $S$ has a greater incentive to invest, i.e., $x_{S}^{*}(\underline{\theta} ; \varnothing) \geq x_{S}^{*}(\underline{\theta} ; \underline{\theta})$. Analogous arguments give: $x_{S}^{*}(\bar{\theta} ; \bar{\theta}) \geq x_{S}^{*}(\bar{\theta} ; \varnothing)$. A marginal change of the posterior belief $P(\varnothing)$ has similar effects on the investment incentives of a concealing firm $S$.

Finally, the ex ante expected equilibrium investments of firms $R$ and $S$ for disclosure strategy $\boldsymbol{\mu}$ are defined as follows:

$$
X_{R}^{*}(\boldsymbol{\mu} ; \sigma) \equiv E_{\theta} E_{m(\theta)}\left\{x_{R}^{*}(m(\theta))\right\} \text {, and } X_{S}^{*}(\boldsymbol{\mu} ; \sigma) \equiv E_{\theta} E_{m(\theta)}\left\{x_{S}^{*}(\theta ; m(\theta))\right\},
$$

respectively, with (for $i \in\{R, S\}$ )

$$
E_{m(\theta)}\left\{x_{i}^{*}(m(\theta))\right\} \equiv \mu(\theta) x_{i}^{*}(\theta)+[1-\mu(\theta)] x_{i}^{*}(\varnothing) .
$$

The ex ante expected equilibrium investment is independent of the disclosure rule, i.e., $X_{i}^{*}(\boldsymbol{\mu} ; \sigma)=\widehat{X}(\sigma)$ for any $\boldsymbol{\mu}$ and $i \in\{R, S\}$, with:

$$
\widehat{X}(\sigma) \equiv \frac{(1-\sigma) V-E(\theta)}{\lambda+V / 2}
$$

This results from the linearity of the equilibrium investments in cost parameter $\theta .{ }^{15}$

\footnotetext{
${ }^{14}$ Combining this fact with the earlier observations that posterior belief $P(\varnothing)$ decreases (increases) in the disclosure probability $\mu(\underline{\theta})$ (respectively, $\mu(\bar{\theta})$ ), gives part (c) of the lemma.

${ }^{15}$ On the one hand, an increase of $\mu(\theta)$ makes it more likely that firm $R$ invests $x_{R}^{*}(\theta)$ instead of $x_{R}^{*}(\varnothing)$. On the other hand, an increase in $\mu(\theta)$ changes firm $R$ 's investment $x_{R}^{*}(\varnothing)$ indirectly through its beliefs. The direct effect exactly offsets the indirect effect. A similar trade-off emerges for firm $S$. By contrast, in Jansen (2001), where equilibrium investments are non-linear functions of parameter $\theta$, the ex ante expected investment under full concealment is smaller than the expected investment under full disclosure.
} 


\subsection{Profits}

In this subsection I study the firms' equilibrium profits for a given disclosure rule. The ex ante expected profit of firm $i$ is defined as follows (for $i \in\{R, S\}$ ):

$$
\Pi_{i}^{*}(\boldsymbol{\mu} ; \sigma) \equiv E_{\theta} E_{m(\theta)}\left\{\pi_{i}\left(\mathbf{x}^{*}(m) ; \theta, \sigma\right)\right\} .
$$

The effect of an increase in the spillover is summarized in the following proposition.

Proposition 1 For any exogenously given disclosure rule $\boldsymbol{\mu}$ and $i \in\{R, S\}$, the ex ante expected equilibrium profit $\Pi_{i}^{*}(\boldsymbol{\mu} ; \sigma)$ is single-peaked in spillover $\sigma$, and is maximized for spillover $\widehat{\sigma}$, with $0<\widehat{\sigma}<\frac{1}{2}$.

The marginal effect of a spillover change on the ex ante expected profits can be decomposed in two effects (for $i, j \in\{R, S\}$ and $i \neq j$ ):

$$
\frac{\partial \Pi_{i}^{*}(\boldsymbol{\mu} ; \sigma)}{\partial \sigma}=E_{\theta} E_{m(\theta)}\left\{\frac{\partial \pi_{i}\left(\mathbf{x}^{*} ; \theta, \sigma\right)}{\partial x_{j}} \cdot \frac{\partial x_{j}^{*}}{\partial \sigma}+\frac{\partial \pi_{i}\left(\mathbf{x}^{*} ; \theta, \sigma\right)}{\partial \sigma}\right\} .
$$

The first term represents an indirect effect. I showed in Lemma 1 (a) that equilibrium investments are decreasing in the spillover, i.e., $\partial x_{j}^{*} / \partial \sigma<0$. The effect of the reduction of the rival's investment on firm $i$ 's expected profit depends on the size of the spillover. This effect is as follows:

$$
\frac{\partial \pi_{i}}{\partial x_{j}}=\left(\sigma-\frac{1}{2} x_{i}\right) V .
$$

If the spillover is sufficiently small, then $\partial \pi_{i} / \partial x_{j}<0$. In that case firm $i$ is better off if its rival's investments are reduced, since the business-stealing effect dominates. If the firms share their revenues equally $\left(\sigma=\frac{1}{2}\right)$, then $\partial \pi_{i} / \partial x_{j}>0$. Hence, for a sufficiently large spillover, and given the own investment, firms would prefer to compete against a rival with high investments, since the free-rider effect is the dominant effect here. The indirect effect is therefore positive for a sufficiently small spillover, and negative for a sufficiently big spillover.

The last term in (3.6) is the direct effect of the spillover on firm $i$ 's profits. On the one hand, expected profits are reduced by $V X_{i}^{*}(\boldsymbol{\mu} ; \sigma)$, since for each unit of a firm's own investment the appropriable revenue is lower. On the other hand, the expected profit is increased by the revenue that spills over from investments of the rival firm, i.e., $V X_{j}^{*}(\boldsymbol{\mu} ; \sigma)$. These two effects exactly offset each other, since expected equilibrium investments are symmetric (Lemma 1d). The direct effect is therefore zero. 
Hence, the overall effect is such that the equilibrium profits are initially increasing, and subsequently decreasing in the spillover. In particular, the spillover $\widehat{\sigma} \in\left(0, \frac{1}{2}\right)$, which maximizes the firms' ex ante expected profits, equals:

$$
\widehat{\sigma}=\frac{V-E(\theta)}{2(\lambda+V)}
$$

and yields a prize structure strictly between winner-take-all and equal-sharing.

\section{Information Disclosure}

So far I considered investments and profits for an exogenously given disclosure rule. This section analyzes the incentives to disclose information.

\subsection{Precommitment to Disclose Information}

The incentive to precommit to an information disclosure rule depends on the effects of disclosure rule changes on the expected profits. The expected profits of firm $R$ and $S$ are, respectively:

$$
\begin{aligned}
\Pi_{R}^{*}(\boldsymbol{\mu} ; \sigma) & =\frac{\lambda}{2} E\left\{\mu(\theta) x_{R}^{*}(\theta)^{2}+[1-\mu(\theta)] x_{R}^{*}(\varnothing)^{2}\right\}+\sigma V X_{R}^{*}(\boldsymbol{\mu} ; \sigma), \text { and } \\
\Pi_{S}^{*}(\boldsymbol{\mu} ; \sigma) & =\frac{\lambda}{2} E\left\{\mu(\theta) x_{S}^{*}(\theta ; \theta)^{2}+[1-\mu(\theta)] x_{S}^{*}(\theta ; \varnothing)^{2}\right\}+\sigma V X_{S}^{*}(\boldsymbol{\mu} ; \sigma) .
\end{aligned}
$$

An immediate implication of Lemma 1 (d) is that the ex ante expected spillover term $\sigma V X_{i}^{*}(\boldsymbol{\mu} ; \sigma)$ is independent of the disclosure rule for any firm $i$. Information disclosure has the following effects for the remaining terms of the expected profit functions.

Proposition 2 For any given spillover $\sigma$, firm $R$ prefers precommitment to full disclosure, and firm $S$ prefers precommitment to full concealment. In particular, $\partial \Pi_{R}^{*} / \partial \mu(\theta)>0$ and $\partial \Pi_{S}^{*} / \partial \mu(\theta)<0$ for any $\theta \in\{\underline{\theta}, \bar{\theta}\}$ and any $\sigma$.

First, an increase of the disclosure probability $\mu(\theta)$ increases the likelihood that firm $R$ is able to adjust its investment level to the firm's actual productivity. This increases the average efficiency of firm $R$ 's decisions, and increases the firm's expected profit. Second, an increase of the disclosure probability, and subsequent investment adjustments by firm $R$, increases the correlation between the firms' investments. The increased correlation between investment levels reduces the expected profit of firm $S$, since investments are strategic substitutes. That is, whereas the expected profit of 
firm $R$ increases in the disclosure probability, the expected profit of firm $S$ decreases in disclosure. Consequently, if firm $S$ can precommit to an information-sharing rule before it learns information $\theta$, then it will choose to conceal all information.

The effects of disclosure are independent of the spillover parameter $\sigma$ for the following reason. Disclosure strategies only affect the variance of the firms' investments, not the mean (Lemma 1d). Conversely, the spillover only affects the average investment level, since it creates a uniform downward shift of investments, and does not affect the variance. Consequently, the effect of disclosure on expected profits does not depend on the size of spillover.

\subsection{Strategic Information Disclosure}

This subsection studies the incentives of firm $S$ to share information after it received information. Firm $S$ anticipates the effects of its disclosure rule on the beliefs of firm $R$, and chooses the disclosure rule which maximizes its expected profit. The proposition below shows that for intermediate spillovers firm $S$ discloses its information only partially or not at all. That is, the "unraveling result" of Okuno-Fujiwara et al. (1990) breaks down for these spillover values. ${ }^{16}$

Proposition 3 The values $\underline{\sigma}_{k}$ and $\bar{\sigma}_{k}$, and continuous functions $\mu^{k}:\left[\underline{\sigma}_{k}, \bar{\sigma}_{k}\right] \rightarrow[0,1]$ exist for $k \in\{L, H\}$, where $0<\underline{\sigma}_{L}<\bar{\sigma}_{L}<\widehat{\sigma}<\underline{\sigma}_{H}<\bar{\sigma}_{H}<\frac{1}{2}$, $\mu^{L}$ is decreasing, with $\mu^{L}\left(\underline{\sigma}_{L}\right)=1$ and $\mu^{L}\left(\bar{\sigma}_{L}\right)=0$, and $\mu^{H}$ is increasing, with $\mu^{H}\left(\underline{\sigma}_{H}\right)=0$ and $\mu^{H}\left(\bar{\sigma}_{H}\right)=1$, such that firm $S$ chooses the following disclosure rule in the unique equilibrium: ${ }^{17}$

(a) if $\sigma \leq \underline{\sigma}_{L}$, then full disclosure with skeptical beliefs, e.g., $\left(\mu^{*}(\underline{\theta}), \mu^{*}(\bar{\theta})\right)=(0,1)$,

(b) if $\underline{\sigma}_{L}<\sigma<\bar{\sigma}_{L}$, then partial disclosure, i.e., $\left(\mu^{*}(\underline{\theta}), \mu^{*}(\bar{\theta})\right)=\left(0, \mu^{L}(\sigma)\right)$,

(c) if $\bar{\sigma}_{L} \leq \sigma \leq \underline{\sigma}_{H}$, then full concealment, i.e., $\left(\mu^{*}(\underline{\theta}), \mu^{*}(\bar{\theta})\right)=(0,0)$,

(d) if $\underline{\sigma}_{H}<\sigma<\bar{\sigma}_{H}$, then partial disclosure, i.e., $\left(\mu^{*}(\underline{\theta}), \mu^{*}(\bar{\theta})\right)=\left(\mu^{H}(\sigma), 0\right)$,

(e) if $\sigma \geq \bar{\sigma}_{H}$, then full disclosure with skeptical beliefs, e.g., $\left(\mu^{*}(\underline{\theta}), \mu^{*}(\bar{\theta})\right)=(1,0)$.

The disclosure probabilities $\mu^{L}(\sigma)$ and $\mu^{H}(\sigma)$ are illustrated in Figure 1 below.

For low spillovers, a firm's profit is decreasing in the rival's investment level, and consequently firm $S$ has an incentive to disclose only bad news. Firm $R$ anticipates

\footnotetext{
${ }^{16} \mathrm{An}$ important condition for unraveling, which is not satisfied here, is monotonicity of firm $S$ 's profit in the rival's strategy. The change in sign of $\partial \pi_{S} / \partial x_{R}$ for an intermediate spillover plays an important role for firm $S$ 's information disclosure incentives.

${ }^{17}$ Strictly speaking, there are several disclosure rules that may be chosen in parts (a) and (e). In particular, $(\mu(\underline{\theta}), \mu(\bar{\theta}))=(q, 1)$ and $(\mu(\underline{\theta}), \mu(\bar{\theta}))=(1, q)$ are equilibrium disclosure rules for any $q \in[0,1]$ in (a) and (e), respectively. But these disclosure rules transmit the same amount of information with skeptical beliefs, i.e., complete information disclosure.
} 


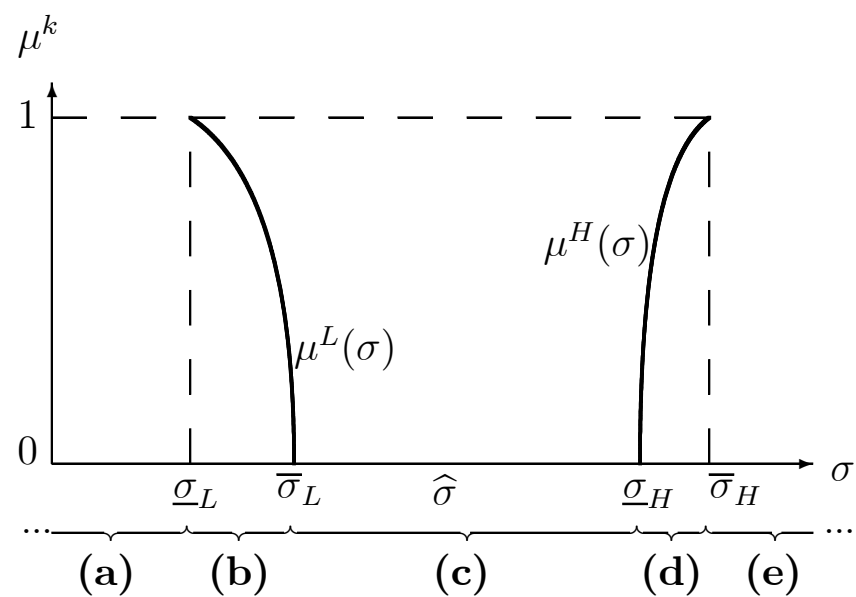

Figure 1: Equilibrium disclosure strategy

this and infers that the concealing firm received low cost information. This eliminates firm $S$ 's possibilities to effectively conceal information. For a sufficiently high spillover the reverse holds, i.e., profits are increasing in the rival's investment level, which gives firm $S$ an incentive to disclose only good news. But the disclosure equilibrium is the same as for low spillovers, i.e., full disclosure with skeptical beliefs. This is the unraveling result, as obtained by, e.g., Grossman (1981) and Milgrom (1981).

For intermediate spillovers the intuition is more subtle. As is clear from expression (3.7), the sign of $\partial \pi_{S} / \partial x_{R}$ depends not only on the spillover size, but also on firm $S$ 's investment $x_{S}$. As was observed in lemma 1 (b), a firm with good news invests more than a firm with bad news. Therefore, given beliefs, a region of intermediate spillover values exists where the following holds. On the one hand, firm $S$ 's profit is decreasing in firm $R$ 's investment, if firm $S$ received good news. But, on the other hand, the firm's profit is increasing in its rival's investment if the firm received bad news. In other words, the firm has countervailing incentives for intermediate spillover values (Lewis and Sappington, 1989). This gives both a firm with good news and a firm with bad news an incentive to conceal information. The firm with good news conceals to discourage investments by its rival (since the firm's profit is decreasing in the rival's investment). But the firm with bad news has an incentive to conceal, because it would like to encourage investments by its rival (since the firm's profit is increasing in its rival's investment). Since both types of firm $S$ have an incentive to conceal its cost information, it can credibly do so. This explains that, for intermediate spillover values, firm $S$ fully conceals the cost in equilibrium. ${ }^{18}$

\footnotetext{
${ }^{18}$ Hendricks and Kovenock (1989) obtain a related non-disclosure result for a common value model of oil exploration. This result is notably different from those of, e.g., Bhattacharya and Ritter (1983),
} 
Partial disclosure emerges as the equilibrium disclosure rule for the remaining spillover values. These spillover values are such that firm $S$ of one type (e.g., $\underline{\theta}$ ) prefers to conceal, whereas the other type (e.g., $\bar{\theta}$ ) is indifferent between disclosure and concealment, given rival's beliefs consistent with such a partial disclosure rule. ${ }^{19}$

The comparison of Propositions 2 and 3 highlights the contrast between the $e x$ ante and ex post incentives of firms to disclose information. The next section argues that this difference in disclosure incentives has some interesting implications.

\section{Implications}

After characterizing the equilibrium strategies, I now analyze the consequences for the equilibrium profits, and the probability of innovation.

\subsection{Effects on Profits}

How does a firm's ex ante expected equilibrium profit depend on the spillover? The overall effect of a marginal change in the spillover $\sigma$ on the expected equilibrium profit is as follows (for $\Pi_{R}^{*}$ and $\Pi_{S}^{*}$ as in (4.1) and (4.2), respectively):

$$
\frac{d \Pi_{i}^{*}\left(\boldsymbol{\mu}^{*}(\sigma) ; \sigma\right)}{d \sigma}=\sum_{\theta \in\{\underline{\theta}, \bar{\theta}\}} \frac{\partial \Pi_{i}^{*}\left(\boldsymbol{\mu}^{*} ; \sigma\right)}{\partial \mu(\theta)} \cdot \frac{d \mu^{*}(\theta)}{d \sigma}+\frac{\partial \Pi_{i}^{*}\left(\boldsymbol{\mu}^{*} ; \sigma\right)}{\partial \sigma}
$$

This expression embodies a trade-off between two effects. On the one hand, an increase of the spillover has a direct effect on the expected equilibrium profit (Proposition 1). This direct effect is captured by the second term of (5.1). On the other hand, a marginal increase of the spillover may also have an indirect effect on the expected equilibrium profit, as is captured by the first term of (5.1). An increase of the spillover may change the equilibrium probability of information disclosure (Proposition 3), which in turn changes a firm's expected profit (Proposition 2).

For the spillover values in the intervals $\left[0, \underline{\sigma}_{L}\right],\left[\bar{\sigma}_{L}, \underline{\sigma}_{H}\right]$, and $\left[\bar{\sigma}_{H}, \frac{1}{2}\right]$, only the direct effect emerges, since for these spillover values the equilibrium disclosure rule does not change with $\sigma$ as Proposition 3 shows. Therefore, the result of Proposition 1 is directly applicable, and the equilibrium profits reach a local maximum in $\widehat{\sigma}$ on the interval $\left[\bar{\sigma}_{L}, \underline{\sigma}_{H}\right]$, where firm $S$ conceals all information.

d'Aspremont et al (1998, 2000), and Anton and Yao (2003, 2004), who focus on separating equilibria.

${ }^{19}$ Proposition 3 could explain the disclosure of intermediate success by IBM, as reported in Choi (1991). Cold superconductivity is a basic innovation, which can have several applications. Hence, the innovation by one firm may be a source of considerable revenues for rivals. As shown, for sufficiently high spillover values, firm $S$ indeed has an incentive to disclose good news with a positive probability. 
For the remaining spillover values, i.e., for spillovers in the intervals $\left(\underline{\sigma}_{L}, \bar{\sigma}_{L}\right)$ and $\left(\underline{\sigma}_{H}, \bar{\sigma}_{H}\right)$, both the direct and indirect effects play a role, since for these values the equilibrium disclosure rule changes in the spillover. The trade-off between these two effects is different for the two firms, as the following proposition shows.

Proposition 4 (a) Firm $S$ 's expected equilibrium profit is single-peaked in $\sigma$, and is maximized for spillover $\widehat{\sigma}$; (b) Firm $R$ 's expected equilibrium profit has three local maxima: each interval $\left[\underline{\sigma}_{L}, \bar{\sigma}_{L}\right)$ and $\left(\underline{\sigma}_{H}, \bar{\sigma}_{H}\right]$, as defined in proposition 3, contains one local maximum, and the third local maximum is reached for $\sigma=\widehat{\sigma}$, with $\widehat{\sigma}$ as defined in (3.8).

For firm $S$ the direct and indirect effects reinforce each other. The equilibrium profit of firm $S$ is illustrated in Figure 2. The upper (lower) thin line represents

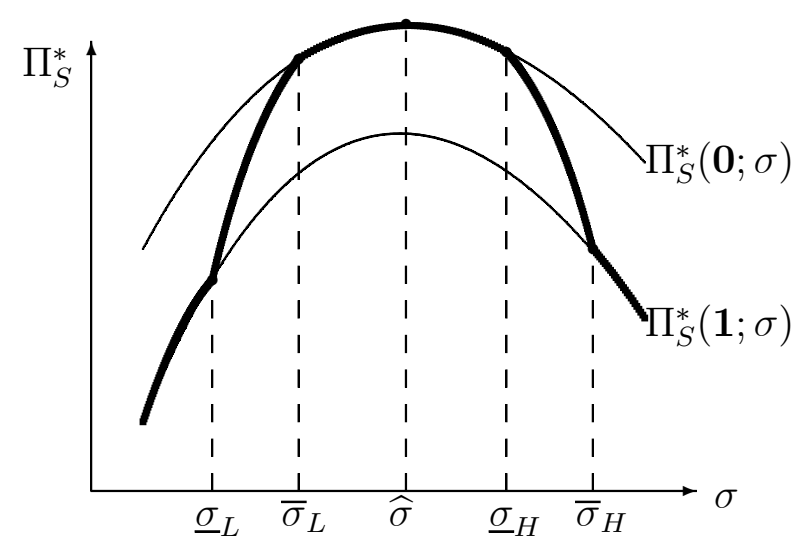

Figure 2: Equilibrium Profit of Firm $S$

the firm's profit under full concealment (full disclosure). The bold line sketches the expected profit for the equilibrium disclosure rule. Firm $S$ expects the highest profit from full concealment (see Proposition 2). For extreme spillover values (i.e., $\sigma<$ $\bar{\sigma}_{L}$ or $\left.\sigma>\underline{\sigma}_{H}\right)$, neither the investment incentives nor the information revelation incentives yield optimal expected profits for firm $S$. But for intermediate spillover values (i.e., $\bar{\sigma}_{L}<\sigma<\underline{\sigma}_{H}$ ) both R\&D incentives (Proposition 1) and disclosure incentives (Proposition 3c) yield the highest expected profits, and expected profits reach a global maximum, as Figure 2 illustrates. Therefore, strategic disclosure has no effect on the choice of the spillover which maximizes the expected profit of firm $S$. However, strategic disclosure does affect the profit locally. In particular, on the interval $\left(\underline{\sigma}_{L}, \bar{\sigma}_{L}\right)$ (resp. $\left.\left(\underline{\sigma}_{H}, \bar{\sigma}_{H}\right)\right)$ the profit increases (decreases) more steeply in the spillover than in the absence of strategic disclosure. 
For firm $R$ the direct effect and indirect effects are in conflict. Figure 3 illustrates firm $R$ 's expected equilibrium profit. The upper (lower) thin line represents

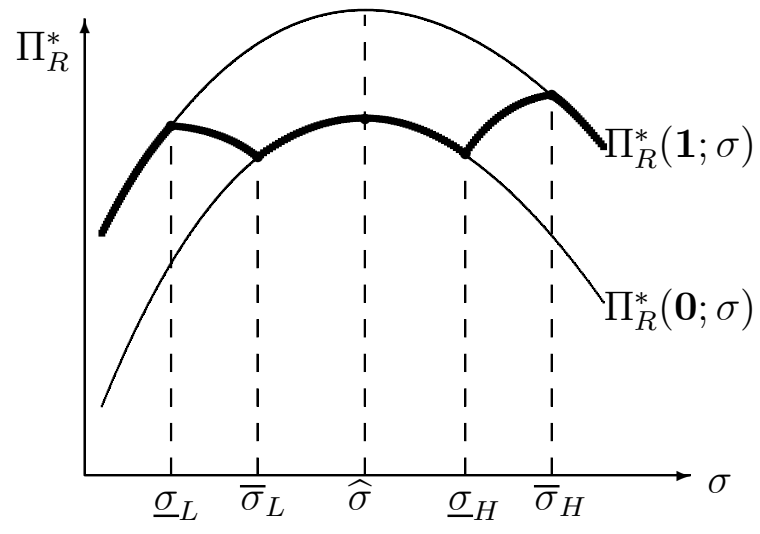

Figure 3: Equilibrium Profit of Firm $R$

the expected profit under full disclosure (full concealment). The bold line sketches the expected profit for the equilibrium disclosure rule. Firm $R$ would earn the highest expected profits if all information were disclosed (Proposition 2). The firm can obtain this level of expected profit only for extreme spillover values (Proposition 3). However, for these spillover values the firms have sub-optimal investment incentives (Proposition 1). Conversely, for intermediate spillovers the strategic disclosure incentives are such that only sub-optimal expected profit levels can be reached, despite better investment incentives. As a consequence of this trade-off between investment incentives and disclosure incentives, two additional local maxima emerge. One emerges on the interval $\left[\underline{\sigma}_{L}, \bar{\sigma}_{L}\right]$, while the other emerges on $\left[\underline{\sigma}_{H}, \bar{\sigma}_{H}\right]$, as Figure 3 illustrates. $^{20}$

\subsection{Effects on Innovation Probability}

Strategic disclosure may also have an effect on the probability of obtaining an innovation. For a given disclosure rule, $\boldsymbol{\mu}$, the expected probability of innovation in equilibrium equals:

$$
I^{*}(\boldsymbol{\mu} ; \sigma) \equiv E_{\theta} E_{m(\theta)}\left\{1-\left[1-x_{R}^{*}(m(\theta))\right]\left[1-x_{S}^{*}(\theta ; m(\theta))\right]\right\} .
$$

This equilibrium probability has the following properties.

Proposition 5 (a) For any exogenously given disclosure rule, $\boldsymbol{\mu}$, the ex ante expected probability of innovation $I^{*}(\boldsymbol{\mu} ; \sigma)$ is decreasing (and concave) in the spillover $\sigma$.

\footnotetext{
${ }^{20}$ The indirect effect dominates at least for spillover values sufficiently close to $\bar{\sigma}_{L}$ and $\underline{\sigma}_{H}$.
} 
(b) For any spillover $\sigma$ the ex ante expected probability of innovation is decreasing in disclosure probability $\mu(\theta)$ for any $\theta$, i.e., $\partial I^{*}(\boldsymbol{\mu} ; \sigma) / \partial \mu(\theta)<0$ for $\theta \in\{\underline{\theta}, \bar{\theta}\}$.

First, the probability of innovation is decreasing in the spillover for any exogenously given disclosure rule, since the equilibrium investments are decreasing in the spillover. Second, disclosure has the following effect on the probability of innovation. The expected probability of innovation under full disclosure is the expected success probability from investments by informed firms, i.e., $E\left\{1-\left[1-x_{R}^{*}(\theta)\right]^{2}\right\}$. The expected probability under full concealment equals the success probability from expected investments by informed firms, i.e., $1-\left[1-E\left\{x_{R}^{*}(\theta)\right\}\right]^{2}$. The success probability from expected investments exceeds the expected success probability from informed firms' investments, since the success probability $1-(1-x)^{2}$ is concave in the investment $x$.

A marginal change of the spillover has the following overall effect on the probability of innovation in equilibrium:

$$
\frac{d I^{*}\left(\boldsymbol{\mu}^{*}(\sigma) ; \sigma\right)}{d \sigma}=\sum_{\theta \in\{\underline{\theta}, \bar{\theta}\}} \frac{\partial I^{*}\left(\boldsymbol{\mu}^{*} ; \sigma\right)}{\partial \mu(\theta)} \cdot \frac{d \mu^{*}(\theta)}{d \sigma}+\frac{\partial I^{*}\left(\boldsymbol{\mu}^{*} ; \sigma\right)}{\partial \sigma} .
$$

As in the profit analysis, a marginal spillover increase yields a trade-off between a direct and an indirect effect. On the one hand, the spillover increase reduces the probability of innovation, as is summarized by the second term of (5.3), which is negative. On the other hand, the spillover increase may affect the equilibrium disclosure rule (Proposition 3), and thereby indirectly change the probability of innovation, since it is decreasing in the disclosure probability. This indirect effect is represented by the first term of (5.3). The trade-off gives the following result.

Proposition 6 The expected probability of innovation in equilibrium, $I^{*}\left(\boldsymbol{\mu}^{*}(\sigma) ; \sigma\right)$, has at most two local maxima. The first local maximum is reached for $\sigma=0$, it always exists, and it is the unique global maximum. If a second local maximum exists, then it is reached for some spillover $\sigma^{o}$ in the interval $\left(\underline{\sigma}_{L}, \bar{\sigma}_{L}\right]$, as defined in proposition 3. In particular, the critical value $\lambda^{\circ}$ exists such that if $\lambda>\lambda^{o}$, then the second local maximum exists, and is reached for $\sigma=\bar{\sigma}_{L}$.

For all spillovers $\sigma \notin\left(\underline{\sigma}_{L}, \bar{\sigma}_{L}\right)$ the probability of innovation is decreasing in the spillover, since the direct and indirect effects are not in conflict. Figure 4 illustrates the expected probability of innovation. The upper (lower) thin line represents the expected success probability for full concealment (resp. full disclosure). The thick line sketches the expected success probability for the equilibrium disclosure rule. Strategic 


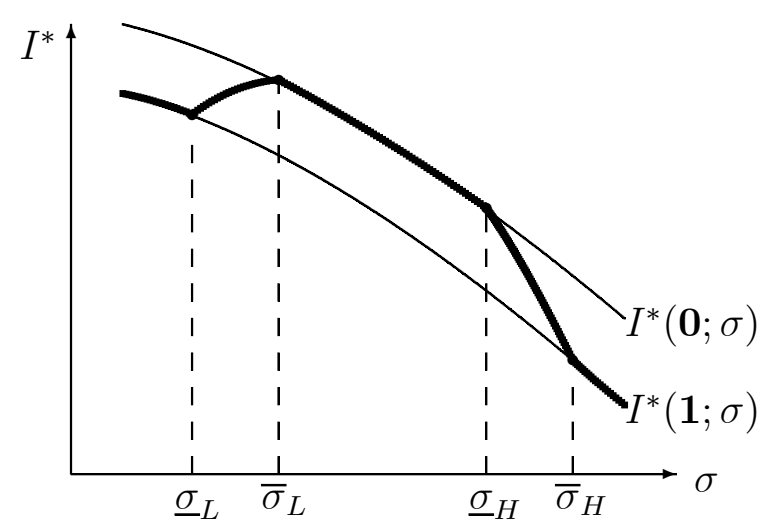

Figure 4: Probability of Innovation

disclosure makes the bold line steeper than any of the thin lines for $\underline{\sigma}_{H}<\sigma<\bar{\sigma}_{H}$, since the indirect effect reinforces the direct effect on this interval.

For $\sigma \in\left(\underline{\sigma}_{L}, \bar{\sigma}_{L}\right)$ the direct and indirect effects are in conflict. On the one hand, the probability of innovation would increase by a spillover reduction for any exogenously given disclosure rule (the second term in 5.3 is always negative). On the other hand, such a spillover reduction increases the disclosure probability $\mu^{L}$ (by Proposition 3 ), which in turn reduces the probability of innovation (the first term of 5.3 is positive). If the marginal cost of investment is sufficiently steep (i.e., $\lambda$ is high), then the indirect effect dominates the direct effect. In this case, the probability of innovation increases by reducing the appropriability of revenues from innovation. This is illustrated in Figure 4 , where the success probability reaches a local maximum for spillover value $\sigma=\bar{\sigma}_{L}$.

Although the probability of innovation may reach a local maximum for $\sigma=\bar{\sigma}_{L}$, the global maximum is unchanged. Perfect appropriability of revenues from innovation $(\sigma=0)$ gives the greatest investments in $\mathrm{R} \& \mathrm{D}$, and the highest probability of innovation (see the Supplementary Appendix).

\section{Discussion}

In this section, I discuss the effects of some extensions on the paper's main results.

\subsection{Information Structure}

The analysis of disclosure incentives in proposition 3 has also implications for the incentives to reveal non-verifiable information. If signals are non-verifiable, then firm 
$S$ may misrepresent them. In fact, it is intuitive and easy to show that firm $S$ can never credibly signal the productivity to firm $R$.

Proposition 7 If information $\theta$ is non-verifiable, then there only exist equilibria in which firm $S$ sends non-informative signals to firm $R$.

First, if firm $R$ believes any message it receives, i.e., it has beliefs consistent with truthful revelation, then firm $S$ has an incentive to misrepresent its cost for any spillover value. Firm $S$ with good (bad) news has an incentive to misrepresent its information, and thereby reduce (increase) the investment of a credulous rival, for any $\sigma<\bar{\sigma}_{H}$ (respectively, $\sigma>\underline{\sigma}_{L}$ ). Since $\underline{\sigma}_{L}<\bar{\sigma}_{H}$, as shown in Proposition 3, there is always a firm type with an incentive to deviate from truthful revelation. Similar incentives are present for less extreme beliefs. Second, for any spillover there exists an equilibrium in which no information is revealed. ${ }^{21}$ This is a standard result for models with non-verifiable signals. Therefore, there only exist equilibria in which firm $S$ sends non-informative signals to firm $R$. This observation extends the result of Ziv (1993) to a setting with spillovers between firms.

The basic model assumes that firm $S$ receives a perfectly informative signal about the firms' R\&D productivity. The introduction of some noise would alter the information and beliefs of firms, since the firms now base their investment decisions on a signal (and the message about the signal), which is positively correlated with $\theta$. But the basic intuition and qualitative results do not change (Jansen, 2004).

Alternatively, the signal of firm $S$ can be imperfect, since the firm may fail to receive information (Dye, 1985, and Farrell, 1986). Uncertainty about the informedness of firm $S$ has the following effects on the R\&D incentives, disclosure incentives, and profits. As before, firm $S$ has an incentive to disclose bad (good) news while concealing good (bad) news for sufficiently low (high) spillover values. The crucial difference with the previous analysis is that these disclosure strategies no longer result in unraveling. Now it remains ambiguous whether firm $S$ is informed and conceals the information, or firm $S$ is uninformed (Shin, 1994, and Jansen, 2008). Despite the altered beliefs and failure of full unraveling, the basic trade-offs in the analysis are unchanged.

Finally, the model can be extended by introducing two-sided asymmetric information without changing the qualitative results (Jansen, 2004).

\footnotetext{
${ }^{21}$ If firm $R$ expects uninformative claims from its rival, it ignores these claims. Consequently, firm $S$ is indifferent between truthful, untruthful, and uninformative claims.
} 


\subsection{Policy Conclusions}

This paper treats the spillover $\sigma$ as a parameter, and performs a comparative statics analysis. In practice, however, firms or policy makers may be able to influence the size of the spillover.

Firms may affect the size of the spillover by adjusting their research design (Katsoulacos and Ulph, 1998, and Kamien and Zang, 2000) or location (Gersbach and Schmutzler, 2003, and Fosfuri and Rønde, 2004). First, if the firms do not coordinate, and they can adjust the spillover choice in the short term, then the individual profits are relevant. Section 3 shows that the firms' interests are aligned if information is exogenous (i.e., both firms prefer to move the spillover in the direction of $\widehat{\sigma}$ ). However, strategic information disclosure may create a conflict of interest between the sender and receiver of information. For spillovers in the intervals $\left[\underline{\sigma}_{L}, \bar{\sigma}_{L}\right]$ and $\left[\underline{\sigma}_{H}, \bar{\sigma}_{H}\right]$ the sender prefers to move the spillover towards $\widehat{\sigma}$, whereas the receiver prefers to move the spillover away from $\widehat{\sigma}$, as section 5.1 shows.

Second, if firms coordinate the spillover choice, or if the choice is a long-term commitment, then the industry profits may be more relevant. ${ }^{22}$ The analysis of the industry profits in equilibrium is analogous to the profit analysis of the individual firms. The effect of information disclosure on the industry profits depends on the size of cost parameter $\lambda$, as Vives (1984) and Kirby (1988) show.

Proposition 8 Firms jointly prefer precommitment to full concealment (disclosure) if $\lambda<\lambda^{*}$ (respectively, $\lambda>\lambda^{*}$ ) where $\lambda^{*} \equiv(1+\sqrt{2}) V / 2$. In particular, $\partial \sum_{i} \Pi_{i}^{*} / \partial \mu(\theta) \gtreqless$ 0 if $\lambda \gtreqless \lambda^{*}$ for any $\theta \in\{\underline{\theta}, \bar{\theta}\}$.

If $\lambda$ is sufficiently low (high), then the firms expects the highest profit from a quid pro quo agreement to conceal (disclose) all information. ${ }^{23}$ Consequently, if $\lambda$ is low, then the effect of a spillover choice on the expected industry profits corresponds to the effect on the sender's expected profit in section 5.1. Conversely, for high values of $\lambda$ the industry's incentives to choose a spillover value correspond to the incentives of the receiver in section 5.1 .

\footnotetext{
${ }^{22}$ For example, each firm maximizes industry profits in a model where the identity of the informed firm $(S)$ is determined randomly at the beginning of the game, and the firms choose the spillover before their roles (i.e., receiver or sender) are determined. Alternatively, industry profits are relevant in a symmetric model with two-sided asymmetric information (Jansen, 2004).

${ }^{23}$ Clearly, if firms precommit to a disclosure rule non-cooperatively, then full information concealment is the dominant strategy, as follows from proposition 2.
} 
Proposition 9 The critical value $\lambda^{* *}$ exists, with $\lambda^{* *}>\lambda^{*}$ (and $\lambda^{*}$ as defined in proposition 2), such that if $\lambda \leq \lambda^{* *}$, then the expected industry profits are single-peaked in $\sigma$, as in Proposition 4 (a), while if $\lambda>\lambda^{* *}$, then the expected equilibrium industry profit has a similar shape as firm $R$ 's expected equilibrium profit in Proposition 4 (b).

A policy maker may affect the size of the spillover by adjusting the strength of intellectual property rights (Denicolò, 1996, and Anton and Yao, 2003, 2004). For a policy maker, the probability of innovation may be important, since it may be related to the economic growth rate, or the consumer surplus. In this case the spillover choice follows from the analysis in section 5.2. A full welfare analysis would have to include the effects of rent dissipation. Unfortunately, such an analysis is less tractable, since equilibrium investments become nonlinear functions of the degree of appropriability. Such an analysis awaits future research.

\section{A Appendix}

In this Appendix I prove Lemma 1, and Propositions 1-9.

\section{Proof of Lemma 1}

The first-order conditions (3.2) and (3.3) yield the following equilibrium R\&D investments of firm $R$ and $S$, respectively (for $m \in\{\theta, \varnothing\}$ and $\theta \in\{\underline{\theta}, \bar{\theta}\}$ ):

$$
\begin{aligned}
x_{R}^{*}(m) & =\frac{(1-\sigma) V-E(\theta \mid m)}{\lambda+V / 2}, \\
x_{S}^{*}(\theta ; m) & =x_{R}^{*}(\theta)+\frac{[E(\theta \mid m)-\theta] V / 2}{\lambda(\lambda+V / 2)}
\end{aligned}
$$

(a) Equilibrium investments are decreasing in $\sigma$, since $\partial x_{R}^{*}(m) / \partial \sigma<0$ for any $m$.

(b) From (A.1) and (A.2) it is immediate that, respectively (for $\theta \in\{\underline{\theta}, \bar{\theta}\}$ ):

$$
\begin{aligned}
x_{R}^{*}(\theta)-x_{R}^{*}(\varnothing) & =\frac{E(\theta \mid \varnothing)-\theta}{\lambda+V / 2}, \text { and } \\
x_{S}^{*}(\theta ; \theta)-x_{S}^{*}(\theta ; \varnothing) & =\frac{-[E(\theta \mid \varnothing)-\theta] V / 2}{\lambda(\lambda+V / 2)} .
\end{aligned}
$$

The inequalities then follow immediately from the inequality $\underline{\theta} \leq E(\theta \mid \varnothing) \leq \bar{\theta}$.

(c) It is easy to verify that (for $\theta \in\{\underline{\theta}, \bar{\theta}\}$ ):

$$
\frac{\partial P(\varnothing)}{\partial \mu(\theta)}=\frac{\operatorname{Pr}(\theta)}{1-E\{\mu(\theta)\}} \cdot \frac{\theta-E\{\theta \mid \varnothing\}}{\bar{\theta}-\underline{\theta}} .
$$


Moreover, it follows immediately from (A.1) and (A.2) that, respectively:

$$
\frac{\partial x_{R}^{*}(\varnothing)}{\partial P(\varnothing)}=\frac{\bar{\theta}-\underline{\theta}}{\lambda+V / 2}>0, \text { and } \frac{\partial x_{S}^{*}(\theta ; \varnothing)}{\partial P(\varnothing)}=\frac{-(\bar{\theta}-\underline{\theta}) V / 2}{\lambda(\lambda+V / 2)}<0 .
$$

Combining (A.5) with (A.6) yields (for $\left.\theta, \theta^{\prime} \in\{\underline{\theta}, \bar{\theta}\}\right)$ :

$$
\begin{aligned}
\frac{\partial x_{R}^{*}(\varnothing)}{\partial \mu(\theta)} & =\frac{\partial x_{R}^{*}(\varnothing)}{\partial P(\varnothing)} \cdot \frac{\partial P(\varnothing)}{\partial \mu(\theta)}=\frac{\operatorname{Pr}(\theta)}{1-E\{\mu(\theta)\}} \cdot \frac{\theta-E\{\theta \mid \varnothing\}}{\lambda+V / 2}, \text { and } \\
\frac{\partial x_{S}^{*}\left(\theta^{\prime} ; \varnothing\right)}{\partial \mu(\theta)} & =\frac{\partial x_{S}^{*}\left(\theta^{\prime} ; \varnothing\right)}{\partial P(\varnothing)} \cdot \frac{\partial P(\varnothing)}{\partial \mu(\theta)}=\frac{-\operatorname{Pr}(\theta)}{1-E\{\mu(\theta)\}} \cdot \frac{[\theta-E\{\theta \mid \varnothing\}] V / 2}{\lambda(\lambda+V / 2)} .
\end{aligned}
$$

The signs of these expressions then follow immediately from $\underline{\theta} \leq E(\theta \mid \varnothing) \leq \bar{\theta}$.

(d) The ex ante expected equilibrium investments of firms $R$ and $S$ equal:

$$
\begin{aligned}
X_{R}^{*}(\boldsymbol{\mu} ; \sigma) & =E\left\{\mu(\theta) x_{R}^{*}(\theta)\right\}+[1-E\{\mu(\theta)\}] x_{R}^{*}(\varnothing), \\
X_{S}^{*}(\boldsymbol{\mu} ; \sigma) & =E\left\{\mu(\theta) x_{S}^{*}(\theta ; \theta)+[1-\mu(\theta)] x_{S}^{*}(\theta ; \varnothing)\right\} .
\end{aligned}
$$

Substituting (A.1) in (A.9), and (A.2) in (A.10), gives $X_{i}^{*}(\boldsymbol{\mu} ; \sigma)=\widehat{X}(\sigma)$ for all $i$.

\section{Proof of Proposition 1}

Lemma 1 (d) implies that $E_{\theta} E_{m(\theta)}\left\{\frac{\partial \pi_{i}\left(\mathbf{x}^{*} ; \theta, \sigma\right)}{\partial \sigma}\right\}=0$ for all $i$ and $\sigma$. Expressions (A.1) and (A.2) imply that $\partial x_{j}^{*} / \partial \sigma=-V /(\lambda+V / 2)$ for all $\theta, m$, and $j \in\{R, S\}$. Using these facts, together with (3.7), reduces (3.6) for $i \in\{R, S\}$ to:

$$
\begin{aligned}
\frac{\partial \Pi_{i}^{*}(\boldsymbol{\mu} ; \sigma)}{\partial \sigma} & =-\left(\sigma-\frac{1}{2} \widehat{X}(\sigma)\right) \cdot \frac{V^{2}}{\lambda+V / 2} \\
& =-\left(\sigma(\lambda+V)-\frac{1}{2}(V-E(\theta))\right) \cdot\left(\frac{V}{\lambda+V / 2}\right)^{2} .
\end{aligned}
$$

Clearly, $\partial \Pi_{i}^{*} / \partial \sigma$ is linear in $\sigma$, with $\partial \Pi_{i}^{*}(\boldsymbol{\mu} ; 0) / \partial \sigma>0>\partial \Pi_{i}^{*}\left(\boldsymbol{\mu} ; \frac{1}{2}\right) / \partial \sigma$, and it is independent of $i$. Hence, $\Pi_{i}^{*}$ is single-peaked in $\sigma$, and the unique spillover $\widehat{\sigma} \in\left(0, \frac{1}{2}\right)$ exists with $\partial \Pi_{i}^{*}(\boldsymbol{\mu} ; \widehat{\sigma}) / \partial \sigma=0$ for any given $\boldsymbol{\mu}$ and $\sigma$, and $i \in\{R, S\}$.

\section{Proof of Proposition 2}

First, differentiating the ex ante expected profit of firm $R$ in (4.1) with respect to $\mu(\theta)$ gives (for some $\theta \in\{\underline{\theta}, \bar{\theta}\}$ ):

$$
\frac{\partial \Pi_{R}^{*}(\boldsymbol{\mu} ; \sigma)}{\partial \mu(\theta)}=\frac{\lambda}{2} \operatorname{Pr}(\theta)\left(x_{R}^{*}(\theta)^{2}-x_{R}^{*}(\varnothing)^{2}\right)+\lambda[1-E\{\mu(\theta)\}] x_{R}^{*}(\varnothing) \frac{\partial x_{R}^{*}(\varnothing)}{\partial \mu(\theta)} .
$$


Using (A.3) to simplify the first term, and (A.7) for the second term, gives:

$$
\begin{aligned}
\frac{\partial \Pi_{R}^{*}(\boldsymbol{\mu} ; \sigma)}{\partial \mu(\theta)} & =\frac{\lambda}{2} \operatorname{Pr}(\theta) \frac{E\{\theta \mid \varnothing\}-\theta}{\lambda+V / 2}\left(x_{R}^{*}(\theta)+x_{R}^{*}(\varnothing)\right)-\lambda \operatorname{Pr}(\theta) \frac{E\{\theta \mid \varnothing\}-\theta}{\lambda+V / 2} x_{R}^{*}(\varnothing) \\
& =\frac{\lambda}{2} \operatorname{Pr}(\theta) \frac{E\{\theta \mid \varnothing\}-\theta}{\lambda+V / 2}\left(x_{R}^{*}(\theta)-x_{R}^{*}(\varnothing)\right) \\
& =\frac{\lambda}{2} \operatorname{Pr}(\theta)\left(\frac{E\{\theta \mid \varnothing\}-\theta}{\lambda+V / 2}\right)^{2}>0 .
\end{aligned}
$$

Second, differentiating firm $S$ 's expected profit (4.2) with respect to $\mu\left(\theta^{\prime}\right)$ gives:

$$
\frac{\partial \Pi_{S}^{*}(\boldsymbol{\mu} ; \sigma)}{\partial \mu\left(\theta^{\prime}\right)}=\frac{\lambda}{2} \operatorname{Pr}\left(\theta^{\prime}\right)\left(x_{S}^{*}\left(\theta^{\prime} ; \theta^{\prime}\right)^{2}-x_{S}^{*}\left(\theta^{\prime} ; \varnothing\right)^{2}\right)+\lambda E\left\{[1-\mu(\theta)] x_{S}^{*}(\theta ; \varnothing) \frac{\partial x_{S}^{*}(\theta ; \varnothing)}{\partial \mu\left(\theta^{\prime}\right)}\right\}
$$

for $\theta^{\prime} \in\{\underline{\theta}, \bar{\theta}\}$. Using (A.4) for the first term, and (A.8) for the second term yields:

$$
\begin{aligned}
\frac{\partial \Pi_{S}^{*}(\boldsymbol{\mu} ; \sigma)}{\partial \mu\left(\theta^{\prime}\right)}= & -\frac{\lambda}{2} \operatorname{Pr}\left(\theta^{\prime}\right) \frac{\left[E(\theta \mid \varnothing)-\theta^{\prime}\right] V / 2}{\lambda(\lambda+V / 2)}\left(x_{S}^{*}\left(\theta^{\prime} ; \theta^{\prime}\right)+x_{S}^{*}\left(\theta^{\prime} ; \varnothing\right)\right) \\
& +\lambda \frac{\operatorname{Pr}\left(\theta^{\prime}\right)}{1-E\{\mu(\theta)\}} \cdot \frac{\left[E\{\theta \mid \varnothing\}-\theta^{\prime}\right] V / 2}{\lambda(\lambda+V / 2)} E\left\{[1-\mu(\theta)] x_{S}^{*}(\theta ; \varnothing)\right\} \\
= & -\frac{\lambda}{2} \operatorname{Pr}\left(\theta^{\prime}\right) \frac{\left[E(\theta \mid \varnothing)-\theta^{\prime}\right] V / 2}{\lambda(\lambda+V / 2)}\left(x_{S}^{*}\left(\theta^{\prime} ; \theta^{\prime}\right)+x_{S}^{*}\left(\theta^{\prime} ; \varnothing\right)-2 x_{R}^{*}(\varnothing)\right) \\
= & -\frac{\lambda}{2} \operatorname{Pr}\left(\theta^{\prime}\right)\left(\frac{E(\theta \mid \varnothing)-\theta^{\prime}}{\lambda+V / 2}\right)^{2} \frac{(2 \lambda+V / 2) V / 2}{\lambda^{2}}<0 .
\end{aligned}
$$

This completes the proof.

\section{Proof of Proposition 3}

Firm $S$ with information $\theta$ expects to earn the following profit from sending message $m$ (for $m \in\{\theta, \varnothing\}$ and $\theta \in\{\underline{\theta}, \bar{\theta}\}$ ):

$$
\pi(m \mid \theta)=\frac{\lambda}{2} x_{S}^{*}(\theta ; m)^{2}+\sigma V x_{R}^{*}(m) .
$$

Hence, using (A.3) and (A.4), the expected profit difference between disclosure and concealment of $\theta$ can be written as follows (for $\theta \in\{\underline{\theta}, \bar{\theta}\}$ ):

$$
\begin{aligned}
\pi(\theta \mid \theta)-\pi(\varnothing \mid \theta) & =\frac{\lambda}{2}\left(x_{S}^{*}(\theta ; \theta)^{2}-x_{S}^{*}(\theta ; \varnothing)^{2}\right)+\sigma V\left(x_{R}^{*}(\theta)-x_{R}^{*}(\varnothing)\right) \\
& =\frac{\lambda}{2} \cdot \frac{-[E(\theta \mid \varnothing)-\theta] V / 2}{\lambda(\lambda+V / 2)}\left(x_{S}^{*}(\theta ; \theta)+x_{S}^{*}(\theta ; \varnothing)\right)+\sigma V \frac{E(\theta \mid \varnothing)-\theta}{\lambda+V / 2} \\
& =\frac{[E(\theta \mid \varnothing)-\theta] V / 2}{\lambda+V / 2}\left(2 \sigma-\frac{1}{2}\left(x_{S}^{*}(\theta ; \theta)+x_{S}^{*}(\theta ; \varnothing)\right)\right) \\
& =\frac{[E(\theta \mid \varnothing)-\theta] V / 2}{(\lambda+V / 2)^{2}}\left(2(\lambda+V) \sigma-\left[V-\theta+\frac{[E(\theta \mid \varnothing)-\theta] V / 2}{2 \lambda}\right]\right)
\end{aligned}
$$


Firm $S$ is indifferent between disclosure and concealment of $\theta$, given rival's beliefs consistent with $\boldsymbol{\mu}$, if $\pi(\theta \mid \theta)=\pi(\varnothing \mid \theta)$, which reduces to: $\sigma=s(\boldsymbol{\mu} ; \theta)$, where

$$
s(\boldsymbol{\mu} ; \theta) \equiv \frac{1}{2(\lambda+V)}\left(V-\theta+\frac{[E(\theta \mid \varnothing)-\theta] V / 2}{2 \lambda}\right) .
$$

The spillover $s(\boldsymbol{\mu} ; \theta)$ is monotonic in $\mu\left(\theta^{\prime}\right)$ for any $\theta, \theta^{\prime} \in\{\underline{\theta}, \bar{\theta}\}$, since differentiating (A.17), and substitution of (A.5) gives:

$$
\frac{\partial s(\boldsymbol{\mu} ; \theta)}{\partial \mu\left(\theta^{\prime}\right)}=\frac{\partial s(\boldsymbol{\mu} ; \theta)}{\partial P(\varnothing)} \cdot \frac{\partial P(\varnothing)}{\partial \mu\left(\theta^{\prime}\right)}=\frac{-\operatorname{Pr}\left(\theta^{\prime}\right)}{1-E\{\mu(\theta)\}} \cdot \frac{\left(\theta^{\prime}-E\{\theta \mid \varnothing\}\right) V / 2}{4 \lambda(\lambda+V)} .
$$

Further, one can show (using the regularity condition 2.1) that for any $\boldsymbol{\mu}$ :

$$
0<s(\boldsymbol{\mu} ; \bar{\theta})<s(\boldsymbol{\mu} ; \underline{\theta})<\frac{1}{2} .
$$

Consequently, there does not exist an equilibrium where firm $S$ randomizes the disclosure of both cost levels. Define: $\underline{\sigma}_{L} \equiv s(0,1 ; \bar{\theta}), \bar{\sigma}_{L} \equiv s(0,0 ; \bar{\theta}), \underline{\sigma}_{H} \equiv s(0,0 ; \underline{\theta})$, and $\bar{\sigma}_{H} \equiv s(1,0 ; \underline{\theta})$.

(a) Suppose that firm $R$ has beliefs consistent with $(\mu(\underline{\theta}), \mu(\bar{\theta}))=(q, 1)$ for $0 \leq$ $q \leq 1$, i.e., $P(\varnothing)=1$. Then firm $S$ has an incentive to disclose bad news, i.e. $\pi(\bar{\theta} \mid \bar{\theta}) \geq \pi(\varnothing \mid \bar{\theta})$, if $\sigma \leq s(q, 1 ; \bar{\theta})$, or $\sigma \leq \underline{\sigma}_{L}$, since $s(q, 1 ; \bar{\theta})=\underline{\sigma}_{L}$ for any $q$.

(b) Now suppose that firm $R$ has beliefs consistent with $(\mu(\underline{\theta}), \mu(\bar{\theta}))=(0, q)$. Then firm $S$ has an incentive to conceal good news, if $\pi(\underline{\theta} \mid \underline{\theta})<\pi(\varnothing \mid \underline{\theta})$, or $\sigma<s(0, q ; \underline{\theta})$. The firm is indifferent between disclosing and concealing bad news, if $\sigma=s(0, q ; \bar{\theta})$. Inequality (A.19) implies that $(0, q)$ is an equilibrium disclosure rule for $\sigma=s(0, q ; \bar{\theta})$. Define $\mu^{L}(\sigma)$ as the inverse of $s(0, q ; \bar{\theta})$, and notice that $\mu^{L}$ is continuous and decreasing for $\underline{\sigma}_{L} \leq \sigma \leq \bar{\sigma}_{L}$ (see A.18).

(c) Firm $S$ conceals all information in equilibrium, if $\pi(\theta \mid \theta)<\pi(\varnothing \mid \theta)$ for all $\theta \in\{\underline{\theta}, \bar{\theta}\}$ and $P(\varnothing)=p$. The firm prefers to conceal good news, if $\sigma \leq \underline{\sigma}_{H}$, and it prefers to conceal bad news, if $\sigma \geq \bar{\sigma}_{L}$. Hence, full concealment is chosen in equilibrium for all spillovers $\bar{\sigma}_{L} \leq \sigma \leq \underline{\sigma}_{H}$.

(d) Analogous to part (b), suppose that firm $R$ has beliefs consistent with $(\mu(\underline{\theta}), \mu(\bar{\theta}))=$ $(q, 0)$ for some $0 \leq q \leq 1$. In that case $\pi(\underline{\theta} \mid \underline{\theta})=\pi(\varnothing \mid \underline{\theta})$ gives $\sigma=s(q, 0 ; \underline{\theta})$, and $\pi(\bar{\theta} \mid \bar{\theta})<\pi(\varnothing \mid \bar{\theta})$ gives $\sigma>s(q, 0 ; \bar{\theta})$. Hence, inequality (A.19) implies that disclosure rule $(q, 0)$ is chosen in equilibrium for $\sigma=s(q, 0 ; \underline{\theta})$. Define $\mu^{H}(\sigma)$ as the inverse of $s(q, 0 ; \underline{\theta})$ for any $0 \leq q \leq 1$ and $\underline{\sigma}_{H} \leq \sigma \leq \bar{\sigma}_{H}$, and notice that $\mu^{H}$ is continuous and increasing (see A.18). 
(e) Analogous to part (a), suppose that firm $S$ chooses $(\mu(\underline{\theta}), \mu(\bar{\theta}))=(1, q)$ for $0 \leq q \leq 1$. Given consistent beliefs (i.e., $P(\varnothing)=0$ ) firm $S$ has an incentive to disclose good news, if $\sigma \geq \bar{\sigma}_{H}$, since $s(1, q ; \underline{\theta})=\bar{\sigma}_{H}$ for any $q$.

Finally, uniqueness of the disclosure equilibrium follows from the monotonicity of $\mu^{L}$ and $\mu^{H}$, and the non-existence of equilibria in which both types choose mixed disclosure strategies. This completes the proof.

\section{Proof of Proposition 4}

For spillover values in $\left[0, \underline{\sigma}_{L}\right],\left[\bar{\sigma}_{L}, \underline{\sigma}_{H}\right]$, and $\left[\bar{\sigma}_{H}, \frac{1}{2}\right]$ the analysis of $(5.1)$ coincides with proposition 1, since disclosure rules are constant on these intervals (see proposition $3 \mathrm{a}, \mathrm{c}$, and e). The analysis for $\left(\underline{\sigma}_{L}, \bar{\sigma}_{L}\right)$ and $\left(\underline{\sigma}_{H}, \bar{\sigma}_{H}\right)$ follows. First, define the type that adopts a mixed disclosure strategy on interval $\left(\underline{\sigma}_{k}, \bar{\sigma}_{k}\right)$ as $\theta_{k}$ for $k \in\{L, H\}$, i.e.:

$$
\theta_{k} \equiv\left\{\begin{array}{l}
\bar{\theta}, \text { if } k=L \\
\underline{\theta}, \text { if } k=H
\end{array}\right.
$$

Second, define the spillover level $\sigma_{L} \equiv s(0, q ; \bar{\theta})$ for some $0<q<1$, and $s($.$) as in$ (A.17), i.e., $\underline{\sigma}_{L}<\sigma_{L}<\bar{\sigma}_{L}$ (see proposition $3 \mathrm{~b}$ ). The equilibrium disclosure rule for $\sigma=\sigma_{L}$ is $\left(\mu^{*}(\underline{\theta}), \mu^{*}(\bar{\theta})\right)=\left(0, \mu^{L}\left(\sigma_{L}\right)\right)=(0, q)$, since $\mu^{L}$ is the inverse of $s\left(0, \mu^{L} ; \bar{\theta}\right)$. Similarly, define $\sigma_{H} \equiv s(q, 0 ; \underline{\theta})$ for some $0<q<1$ (i.e., $\underline{\sigma}_{H}<\sigma_{H}<\bar{\sigma}_{H}$ and $\left.\boldsymbol{\mu}^{*}\left(\sigma_{H}\right)=(q, 0)\right)$. Applying the implicit function theorem yields (for $k \in\{L, H\}$ ):

$$
\frac{d \mu^{k}\left(\sigma_{k}\right)}{d \sigma}=\frac{1}{\frac{\partial s\left(\boldsymbol{\mu}^{*}\left(\sigma_{k}\right) ; \theta_{k}\right)}{\partial \mu\left(\theta_{k}\right)}}
$$

Hence, evaluating (5.1) at $\sigma=\sigma_{k}$ (for $i \in\{R, S\}$ and $k \in\{L, H\}$ ) reduces to:

$$
\frac{d \Pi_{i}^{*}\left(\boldsymbol{\mu}^{*}\left(\sigma_{k}\right) ; \sigma_{k}\right)}{d \sigma}=\frac{\partial \Pi_{i}^{*}\left(\boldsymbol{\mu}^{*}\left(\sigma_{k}\right) ; \sigma_{k}\right)}{\partial \mu\left(\theta_{k}\right)} \cdot \frac{1}{\left(\frac{\partial s\left(\boldsymbol{\mu}^{*}\left(\sigma_{k}\right) ; \theta_{k}\right)}{\partial \mu\left(\theta_{k}\right)}\right)}+\frac{\partial \Pi_{i}^{*}\left(\boldsymbol{\mu}^{*}\left(\sigma_{k}\right) ; \sigma_{k}\right)}{\partial \sigma} .
$$

The proof proceeds by evaluating the signs of (A.22) for $k \in\{L, H\}$ and $i \in\{R, S\}$.

(a) The analysis of (5.1) for $i=S$ gives immediately that both terms are positive (negative) if $\sigma=\sigma_{L}$ (resp. $\sigma=\sigma_{H}$ ) for any $q \in(0,1)$.

(b) Dividing (A.12) by (A.18) yields:

$$
\begin{aligned}
\frac{\partial \Pi_{R}^{*}(\boldsymbol{\mu} ; \sigma)}{\partial \mu(\theta)} \cdot \frac{1}{\left(\frac{\partial s(\boldsymbol{\mu} ; \theta)}{\partial \mu(\theta)}\right)} & =\frac{\lambda}{2} \operatorname{Pr}(\theta)\left(\frac{E\{\theta \mid \varnothing\}-\theta}{\lambda+V / 2}\right)^{2} \frac{1}{\frac{-\operatorname{Pr}(\theta)}{1-E\{\mu(\theta)\}} \cdot \frac{(\theta-E\{\theta \mid \varnothing\}) V / 2}{4 \lambda(\lambda+V)}} \\
& =\frac{E\{\theta \mid \varnothing\}-\theta}{(\lambda+V / 2)^{2}} 2[1-E\{\mu(\theta)\}] \frac{\lambda+V}{V / 2} \lambda^{2} .
\end{aligned}
$$


Second, evaluating (A.11) at $\sigma=\sigma_{k}$, and using the definition $\sigma_{k}=s\left(\boldsymbol{\mu}^{*}\left(\sigma_{k}\right) ; \theta_{k}\right)$, with $s($.$) as defined in (A.17), gives (for i \in\{R, S\}$ ):

$$
\begin{aligned}
\frac{\partial \Pi_{i}^{*}\left(\boldsymbol{\mu}^{*}\left(\sigma_{k}\right) ; \sigma_{k}\right)}{\partial \sigma} & =-\frac{1}{2}\left(\frac{\left[E\{\theta \mid \varnothing\}-\theta_{k}\right] V / 2}{2 \lambda}+E(\theta)-\theta_{k}\right)\left(\frac{V}{\lambda+V / 2}\right)^{2} \\
& =\frac{-\left[E\{\theta \mid \varnothing\}-\theta_{k}\right]}{(\lambda+V / 2)^{2}}\left(\frac{V / 2}{\lambda}+2\left[1-E\left\{\mu^{*}(\theta)\right\}\right]\right)(V / 2)^{2}(A
\end{aligned}
$$

since $E(\theta)-\theta_{k}=\left[1-E\left\{\mu^{*}(\theta)\right\}\right]\left[E\{\theta \mid \varnothing\}-\theta_{k}\right]$ if $\sigma=\sigma_{k}$ for $k \in\{L, H\}$. Substitution of (A.23), evaluated at $\boldsymbol{\mu}^{*}\left(\sigma_{k}\right), \sigma_{k}$ and $\theta_{k}$, and (A.24) in (A.22) for $i=R$ gives:

$$
\begin{aligned}
\frac{d \Pi_{R}^{*}\left(\boldsymbol{\mu}^{*}\left(\sigma_{k}\right) ; \sigma_{k}\right)}{d \sigma}= & \frac{E\{\theta \mid \varnothing\}-\theta_{k}}{(\lambda+V / 2)^{2}} 2\left[1-E\left\{\mu^{*}(\theta)\right\}\right] \frac{\lambda+V}{V / 2} \lambda^{2} \\
& -\frac{E\{\theta \mid \varnothing\}-\theta_{k}}{(\lambda+V / 2)^{2}}\left(\frac{V / 2}{\lambda}+2\left[1-E\left\{\mu^{*}(\theta)\right\}\right]\right)(V / 2)^{2} \\
= & \frac{E\{\theta \mid \varnothing\}-\theta_{k}}{V / 2(\lambda+V / 2)^{2}} h(\lambda, q)
\end{aligned}
$$

where

$$
h(\lambda, q) \equiv 2\left[1-\operatorname{Pr}\left(\theta_{k}\right) q\right]\left((\lambda+V) \lambda^{2}-(V / 2)^{3}\right)-\frac{(V / 2)^{4}}{\lambda} .
$$

Evaluating this expression for $q \rightarrow 0$ (i.e. $\sigma_{L} \rightarrow \bar{\sigma}_{L}$, and $\sigma_{H} \rightarrow \underline{\sigma}_{H}$ ) yields:

$$
\lim _{\sigma \uparrow \bar{\sigma}_{L}} \frac{d \Pi_{R}^{*}\left(\boldsymbol{\mu}^{*}(\sigma) ; \sigma\right)}{d \sigma}<0, \text { and } \lim _{\sigma \downarrow \underline{\sigma}_{H}} \frac{d \Pi_{R}^{*}\left(\boldsymbol{\mu}^{*}(\sigma) ; \sigma\right)}{d \sigma}>0,
$$

respectively. Moreover, $h(\lambda, q)$ in (A.26) is monotonic in $q$, and therefore it changes sign at most once on the interval $\left(\underline{\sigma}_{k}, \bar{\sigma}_{k}\right)$ for $k \in\{L, H\}$. Hence, one local maximum is reached on the interval $\left[\underline{\sigma}_{k}, \bar{\sigma}_{k}\right]$ for $k \in\{L, H\}$.

\section{Proof of Proposition 5}

This proof is similar to the proofs of Propositions 1 and 2. Therefore, I only report the results of derivations. First, the effect of the spillover on the probability of innovation equals:

$$
\begin{aligned}
\frac{\partial I^{*}(\boldsymbol{\mu} ; \sigma)}{\partial \sigma} & =E_{\theta} E_{m(\theta)}\left\{\frac{\partial x_{R}^{*}(m)}{\partial \sigma}\left[1-x_{S}^{*}(\theta ; m)\right]+\left[1-x_{R}^{*}(m)\right] \frac{\partial x_{S}^{*}(\theta ; m)}{\partial \sigma}\right\} \\
& =\frac{-2 V}{\lambda+V / 2}(1-\widehat{X}(\sigma))<0 .
\end{aligned}
$$


Second, the effect of the disclosure probability on the probability of innovation equals:

$$
\begin{aligned}
\frac{\partial I^{*}(\boldsymbol{\mu} ; \sigma)}{\partial \mu\left(\theta^{\prime}\right)}= & \operatorname{Pr}\left(\theta^{\prime}\right)\left(\left[1-x_{R}^{*}(\varnothing)\right]\left[1-x_{S}^{*}\left(\theta^{\prime} ; \varnothing\right)\right]-\left[1-x_{R}^{*}\left(\theta^{\prime}\right)\right]\left[1-x_{S}^{*}\left(\theta^{\prime} ; \theta^{\prime}\right)\right]\right) \\
& +E\left\{[1-\mu(\theta)]\left(\frac{\partial x_{R}^{*}(\varnothing)}{\partial \mu\left(\theta^{\prime}\right)}\left[1-x_{S}^{*}(\theta ; \varnothing)\right]+\left[1-x_{R}^{*}(\varnothing)\right] \frac{\partial x_{S}^{*}(\theta ; \varnothing)}{\partial \mu\left(\theta^{\prime}\right)}\right)\right\} \\
= & -\operatorname{Pr}\left(\theta^{\prime}\right)\left(\frac{E\{\theta \mid \varnothing\}-\theta^{\prime}}{\lambda+V / 2}\right)^{2}<0
\end{aligned}
$$

for any $\theta^{\prime} \in\{\underline{\theta}, \bar{\theta}\}$. This completes the proof.

\section{Proof of Proposition 6}

This proof is similar to the proof of proposition 4 . The existence of the first local maximum at $\sigma=0$, and the absence of further local maxima on the interval $\left(0, \underline{\sigma}_{L}\right] \cup\left(\bar{\sigma}_{L}, \frac{1}{2}\right]$ follows immediately from monotonicity of $I^{*}\left(\boldsymbol{\mu}^{*}(\sigma) ; \sigma\right)$ on the interval, as implied by propositions 3 and 5, and (5.3). First, I show that there exists at most one local maximum on the remaining interval $\left(\underline{\sigma}_{L}, \bar{\sigma}_{L}\right]$. As in the proof of proposition 4 , take $\sigma_{L} \equiv s(0, q ; \bar{\theta})$ for some $0<q \leq 1$, with $s$ as in (A.17), and evaluate (5.3) at $\sigma=\sigma_{L}$ :

$$
\frac{d I^{*}\left(\boldsymbol{\mu}^{*}\left(\sigma_{L}\right) ; \sigma_{L}\right)}{d \sigma}=\frac{\partial I^{*}\left(0, q ; \sigma_{L}\right)}{\partial \mu(\bar{\theta})} \cdot \frac{1}{\partial s(0, q ; \bar{\theta}) / \partial \mu(\bar{\theta})}+\frac{\partial I^{*}\left(0, q ; \sigma_{L}\right)}{\partial \sigma}
$$

Using (A.28) and (A.18), the first term of (A.29) reduces to:

$$
\frac{\partial I^{*}\left(0, q ; \sigma_{L}\right)}{\partial \mu(\bar{\theta})} \cdot \frac{1}{\partial s(0, q ; \bar{\theta}) / \partial \mu(\bar{\theta})}=\frac{4}{(\lambda+V / 2)^{2}} \cdot \frac{p(\bar{\theta}-\underline{\theta}) \lambda(\lambda+V)}{V / 2}
$$

Evaluating (A.27) at $\sigma=\sigma_{L}$ reduces the second term of (A.29) to:

$\frac{\partial I^{*}\left(0, q ; \sigma_{L}\right)}{\partial \sigma}=\frac{-4}{(\lambda+V / 2)^{2}} \cdot \frac{V / 2}{\lambda+V}\left[(\lambda+V / 2)(\lambda+E(\theta))-(\bar{\theta}-\underline{\theta}) V / 2\left(p+P(\varnothing) \frac{V / 2}{2 \lambda}\right)\right]$

with $P(\varnothing)=p /[1-q(1-p)]$. Clearly, $d I^{*}\left(\boldsymbol{\mu}^{*}\left(\sigma_{L}\right) ; \sigma_{L}\right) / d \sigma$ is increasing in $q$, since the first term is constant in $q$, and the second term is increasing in $q$. This implies that $I^{*}\left(\boldsymbol{\mu}^{*}(\sigma) ; \sigma\right)$ is concave in $\sigma$ for $\sigma \in\left(\underline{\sigma}_{L}, \bar{\sigma}_{L}\right]$, since $\sigma_{L}$ is decreasing in $q$. Concavity implies in turn that a local maximum on the interval is unique, if it exists.

Second, if (A.29) is positive for any feasible $\sigma_{L}$ (or $q$ ), then a local maximum exists at $\sigma=\bar{\sigma}_{L}$. The derivations above imply that for any $\sigma \in\left(\underline{\sigma}_{L}, \bar{\sigma}_{L}\right]$ :

$$
\begin{aligned}
\frac{d I^{*}\left(\boldsymbol{\mu}^{*}(\sigma) ; \sigma\right)}{d \sigma} & >\frac{4}{(\lambda+V / 2)^{2}}\left(\frac{p(\bar{\theta}-\underline{\theta}) \lambda(\lambda+V)}{V / 2}-\frac{(\lambda+V / 2)(\lambda+E(\theta)) V / 2}{\lambda+V}\right) \\
& =\frac{4}{(\lambda+V / 2)^{2}} \cdot \frac{F(\lambda)}{(\lambda+V) V / 2}
\end{aligned}
$$


with

$$
F(\lambda) \equiv p(\bar{\theta}-\underline{\theta}) \lambda(\lambda+V)^{2}-(\lambda+V / 2)(\lambda+E(\theta))(V / 2)^{2}
$$

Clearly, $F$ is convex and increasing in $\lambda$ for sufficiently high values of $\lambda$. Therefore, there exists a critical value for $\lambda$ beyond which $F$ is positive.

\section{Proof of Proposition 7}

Suppose the statement is not true. In other words, suppose there is an equilibrium in which firm $S$ sends informative messages, e.g. $m \in\{L, H\}$ and w.l.o.g. $E\{\theta \mid L\}<$ $E\{\theta \mid H\}$. The expected profit of firm $S$ with information $\theta$ for sending message $m$ is $\pi(m \mid \theta)$ as defined in (A.16). Similar steps as in the proof of proposition 3 give:

$$
\begin{aligned}
\pi(L \mid \theta)-\pi(H \mid \theta)= & \frac{[E(\theta \mid H)-E(\theta \mid L)] V / 2}{(\lambda+V / 2)^{2}} . \\
& \cdot\left[2 \sigma(\lambda+V)-\left(V-\theta+\frac{[E(\theta \mid L)+E(\theta \mid H)-2 \theta] V / 2}{2 \lambda}\right)\right]
\end{aligned}
$$

Since $E\{\theta \mid L\}<E\{\theta \mid H\}$, firm $S$ with cost $\theta$ prefers message $L$, iff $\sigma>s^{o}(\theta)$, with

$$
s^{o}(\theta) \equiv \frac{1}{2(\lambda+V)}\left(V-\theta+\frac{[E(\theta \mid L)+E(\theta \mid H)-2 \theta] V / 2}{2 \lambda}\right)
$$

Monotonicity of $s^{o}(\theta)$ in $\theta$ gives the following optimal message strategy for firm $S$ :

$$
(m(\underline{\theta}), m(\bar{\theta}))=\left\{\begin{array}{l}
(H, H), \text { if } \sigma \leq s^{o}(\bar{\theta}) \\
(H, L), \text { if } s^{o}(\overline{\bar{\theta}}) \leq \sigma \leq s^{o}(\underline{\theta}) \\
(L, L), \text { if } \sigma \geq s^{o}(\underline{\theta})
\end{array}\right.
$$

This message strategy is always inconsistent with firm $R$ 's beliefs, i.e. the assumption $E\{\theta \mid L\}<E\{\theta \mid H\}$. This contradiction completes the proof.

\section{Proof of Proposition 8}

Taking the sum of (A.13) and (A.15), immediately yields the following:

$$
\begin{aligned}
\frac{\partial \sum_{i} \Pi_{i}^{*}(\boldsymbol{\mu} ; \sigma)}{\partial \mu\left(\theta^{\prime}\right)} & =\frac{\partial \Pi_{R}^{*}(\boldsymbol{\mu} ; \sigma)}{\partial \mu\left(\theta^{\prime}\right)}+\frac{\partial \Pi_{S}^{*}(\boldsymbol{\mu} ; \sigma)}{\partial \mu\left(\theta^{\prime}\right)} \\
& =\frac{\lambda}{2} \operatorname{Pr}\left(\theta^{\prime}\right)\left(\frac{E\{\theta \mid \varnothing\}-\theta^{\prime}}{\lambda+V / 2}\right)^{2} \frac{\lambda^{2}-2 \lambda V / 2-(V / 2)^{2}}{\lambda^{2}}
\end{aligned}
$$

which is positive (negative) iff $\lambda>\lambda^{*}$ (resp. $\lambda<\lambda^{*}$ ), as stated in the proposition. 


\section{Proof of Proposition 9}

Comparison of (A.13) and (A.30) gives:

$$
\frac{\partial \sum_{i} \Pi_{i}^{*}(\boldsymbol{\mu} ; \sigma)}{\partial \mu(\theta)} \cdot \frac{1}{\frac{\partial s(\boldsymbol{\mu} ; \theta)}{\partial \mu(\theta)}}=\left(\frac{\partial \Pi_{R}^{*}(\boldsymbol{\mu} ; \sigma)}{\partial \mu(\theta)} \cdot \frac{1}{\frac{\partial s(\boldsymbol{\mu} ; \theta)}{\partial \mu(\theta)}}\right) \frac{\lambda^{2}-2 \lambda V / 2-(V / 2)^{2}}{\lambda^{2}} .
$$

Substitution of (A.23) in (A.31), and adding $\sum_{i} \partial \Pi_{i}^{*}\left(\boldsymbol{\mu}^{*}\left(\sigma_{k}\right) ; \sigma_{k}\right) / \partial \sigma$ from (A.24) yields:

$$
\begin{aligned}
& \frac{d \sum_{i} \Pi_{i}^{*}\left(\boldsymbol{\mu}^{*}\left(\sigma_{k}\right) ; \sigma_{k}\right)}{d \sigma}=2 \frac{E\{\theta \mid \varnothing\}-\theta_{k}}{V / 2(\lambda+V / 2)^{2}} . \\
& \cdot\left(\left[1-E\left\{\mu^{*}(\theta)\right\}\right]\left[(\lambda+V)\left(\lambda^{2}-2 \lambda V / 2-(V / 2)^{2}\right)-2(V / 2)^{3}\right]-\frac{(V / 2)^{4}}{\lambda}\right) \\
= & 2 \frac{E\{\theta \mid \varnothing\}-\theta_{k}}{\lambda V / 2(\lambda+V / 2)^{2}} H(\lambda, q),
\end{aligned}
$$

with

$$
H(\lambda, q) \equiv\left[1-\operatorname{Pr}\left(\theta_{k}\right) q\right] \lambda(\lambda+V / 2)\left(\lambda^{2}-\lambda V / 2-4(V / 2)^{2}\right)-(V / 2)^{4}
$$

Clearly, $\lambda^{2}-\lambda V / 2-4(V / 2)^{2}$ is increasing in $\lambda$, and has the root $\lambda^{\prime} \equiv(1+\sqrt{17}) V / 4$, i.e. $\lambda^{\prime}>\lambda^{*}$. Consequently, if $\lambda \leq \lambda^{\prime}$, then $H(\lambda, q)<0$ for any $q$. If $\lambda>\lambda^{\prime}$, then $H(\lambda, q)$ is decreasing in $q$, and increasing in $\lambda$. Define $\lambda^{* *}$ such that $H\left(\lambda^{* *}, 0\right)=0$, i.e., $\lambda^{* *}>\lambda^{\prime}$. First, if $\lambda^{\prime}<\lambda<\lambda^{* *}$, then $H(\lambda, 0)<0$, and therefore $H(\lambda, q)<0$ for any $q$, i.e., equilibrium industry profits are single-peaked, as in Proposition 4 (a). Second, if $\lambda>\lambda^{* *}$, then $H(\lambda, 0)>0$, which implies that $\lim _{\sigma \uparrow \bar{\sigma}_{L}} d \sum_{i} \Pi_{i}^{*}\left(\boldsymbol{\mu}^{*}(\sigma) ; \sigma\right) / d \sigma<0$ and $\lim _{\sigma \downarrow \underline{\sigma}_{H}} d \sum_{i} \Pi_{i}^{*}\left(\boldsymbol{\mu}^{*}(\sigma) ; \sigma\right) / d \sigma>0$. Moreover, $d \sum_{i} \Pi_{i}^{*}\left(\boldsymbol{\mu}^{*}(\sigma) ; \sigma\right) / d \sigma$ changes sign at most once on the interval $\left(\underline{\sigma}_{k}, \bar{\sigma}_{k}\right)$ for $k \in\{L, H\}$, since $H$ is monotonic in $q$. Hence, one local maximum is reached on the interval $\left[\underline{\sigma}_{k}, \bar{\sigma}_{k}\right]$ for $k \in\{L, H\}$ as in Proposition 4 (b). 


\section{B Supplementary Appendix}

Here I prove Propositions 10 and 11, which are related to the maximization of profits and innovation probability, respectively.

Proposition 10 The critical cost parameter $\lambda^{* * *}$ exists, with $\lambda^{* * *}>\lambda^{* *}$, such that for all $\lambda \geq \lambda^{* * *}$ neither firm $R$ 's expected equilibrium profit nor the expected equilibrium industry profit reach a global maximum in $\sigma=\widehat{\sigma}$, i.e., the spillovers $\sigma^{\prime}$ and $\sigma^{\prime \prime}$ exist such that $\Pi_{R}^{*}\left(\boldsymbol{\mu}^{*}\left(\sigma^{\prime}\right) ; \sigma^{\prime}\right)>\Pi_{R}^{*}\left(\boldsymbol{\mu}^{*}(\widehat{\sigma}) ; \widehat{\sigma}\right)$, and $\sum_{i} \Pi_{i}^{*}\left(\boldsymbol{\mu}^{*}\left(\sigma^{\prime \prime}\right) ; \sigma^{\prime \prime}\right)>\sum_{i} \Pi_{i}^{*}\left(\boldsymbol{\mu}^{*}(\widehat{\sigma}) ; \widehat{\sigma}\right)$.

Proof: (a) First, for $\boldsymbol{\mu}^{*}$ and $\sigma=\widehat{\sigma}$ the expected equilibrium profit of firm $R$ in (4.1) equals:

$$
\Pi_{R}^{*}\left(\boldsymbol{\mu}^{*}(\widehat{\sigma}) ; \widehat{\sigma}\right)=\Pi_{R}^{*}(\mathbf{0} ; \widehat{\sigma})=\left(\frac{\lambda}{2} \widehat{X}(\widehat{\sigma})+\widehat{\sigma} V\right) \widehat{X}(\widehat{\sigma})
$$

since $x_{R}^{*}(\varnothing)=\widehat{X}(\sigma)$ for $\boldsymbol{\mu}=\mathbf{0}$. Second, evaluate firm $R$ 's expected equilibrium profit at spillover value $\widetilde{\sigma} \in\left\{\underline{\sigma}_{L}, \bar{\sigma}_{H}\right\}$, i.e., $\boldsymbol{\mu}^{*}(\widetilde{\sigma}) \in\{(0,1),(1,0)\}$ implying full disclosure in equilibrium (using definitions A.1 and 3.4):

$$
\begin{aligned}
\Pi_{R}^{*}\left(\boldsymbol{\mu}^{*}(\widetilde{\sigma}) ; \widetilde{\sigma}\right)= & \frac{\lambda}{2} E\left\{x_{R}^{*}(\theta)^{2}\right\}+\widetilde{\sigma} V \widehat{X}(\widetilde{\sigma}) \\
= & \frac{\lambda}{2} E\left\{\left(\frac{(1-\widetilde{\sigma}) V-E(\theta)-[\theta-E(\theta)]}{\lambda+V / 2}\right)^{2}\right\}+\widetilde{\sigma} V \widehat{X}(\widetilde{\sigma}) \\
= & \left(\frac{\lambda}{2} \widehat{X}(\widetilde{\sigma})+\widetilde{\sigma} V\right) \widehat{X}(\widetilde{\sigma})+\frac{\lambda}{2} \cdot \frac{\operatorname{Var}(\theta)}{(\lambda+V / 2)^{2}} \\
= & \left(\frac{\lambda}{2} \widehat{X}(\widehat{\sigma})+\widehat{\sigma} V-\frac{1}{2}(\lambda+V) \frac{(\widehat{\sigma}-\widetilde{\sigma}) V}{\lambda+V / 2}\right)\left[\widehat{X}(\widehat{\sigma})+\frac{(\widehat{\sigma}-\widetilde{\sigma}) V}{\lambda+V / 2}\right] \\
& +\frac{\lambda}{2} \cdot \frac{V a r(\theta)}{(\lambda+V / 2)^{2}} \\
= & \left(\frac{\lambda}{2} \widehat{X}(\widehat{\sigma})+\widehat{\sigma} V\right) \widehat{X}(\widehat{\sigma})-\frac{1}{2}(\lambda+V)\left(\frac{(\widehat{\sigma}-\widetilde{\sigma}) V}{\lambda+V / 2}\right)^{2}+\frac{\lambda \cdot \operatorname{Var}(\theta)}{2(\lambda+V / 2)^{2}} \\
& +\left(\frac{\lambda}{2} \widehat{X}(\widehat{\sigma})+\widehat{\sigma} V-\frac{1}{2}(\lambda+V) \widehat{X}(\widehat{\sigma})\right) \frac{(\widehat{\sigma}-\widetilde{\sigma}) V}{\lambda+V / 2} \\
= & \Pi_{R}^{*}\left(\boldsymbol{\mu}^{*}(\widehat{\sigma}) ; \widehat{\sigma}\right)-\frac{1}{2}(\lambda+V)\left(\frac{(\widehat{\sigma}-\widetilde{\sigma}) V}{\lambda+V / 2}\right)^{2}+\frac{\lambda \cdot \operatorname{Var}(\theta)}{2(\lambda+V / 2)^{2}}, \quad(\mathrm{~B} .2)
\end{aligned}
$$

since $\frac{\lambda}{2} \widehat{X}(\widehat{\sigma})+\widehat{\sigma} V=\frac{1}{2}(V-E(\theta))$, and $\widehat{X}(\widehat{\sigma})=(V-E(\theta)) /(\lambda+V)$, as follows from (3.4) and (3.8). Recall that: $\underline{\sigma}_{L}=s(0,1 ; \bar{\theta})$ and $\bar{\sigma}_{H}=s(1,0 ; \underline{\theta})$, with $s(\boldsymbol{\mu} ; \theta)$, as in 
(A.17). The spillover $\underline{\sigma}_{L}$ can be rewritten as follows (using definition 3.8):

$$
\begin{aligned}
\underline{\sigma}_{L} & =s(0,1 ; \bar{\theta})=\frac{1}{2(\lambda+V)}\left(V-\bar{\theta}-\frac{(\bar{\theta}-\underline{\theta}) V / 2}{2 \lambda}\right) \\
& =\frac{1}{2(\lambda+V)}\left(V-E(\theta)-\frac{p 2 \lambda+V / 2}{2 \lambda}(\bar{\theta}-\underline{\theta})\right)=\widehat{\sigma}-\frac{p 2 \lambda+V / 2}{4 \lambda(\lambda+V)}(\bar{\theta}-\underline{\theta})
\end{aligned}
$$

Similarly, $\bar{\sigma}_{H}=s(1,0 ; \underline{\theta})=\widehat{\sigma}+[(1-p) 2 \lambda+V / 2](\bar{\theta}-\underline{\theta}) /[4 \lambda(\lambda+V)]$. Moreover, $\operatorname{Var}(\theta)=p(1-p)(\bar{\theta}-\underline{\theta})^{2}$. Hence, $\Pi_{R}^{*}\left(\boldsymbol{\mu}^{*}(\widetilde{\sigma}) ; \widetilde{\sigma}\right)$ in (B.2) can be written as follows (for $\theta \in\{\underline{\theta}, \bar{\theta}\})$ :

$$
\Pi_{R}^{*}\left(\boldsymbol{\mu}^{*}(\widetilde{\sigma}) ; \widetilde{\sigma}\right)=\Pi_{R}^{*}\left(\boldsymbol{\mu}^{*}(\widehat{\sigma}) ; \widehat{\sigma}\right)+\frac{(\bar{\theta}-\underline{\theta})^{2}}{2(\lambda+V / 2)^{2}} g(\lambda ; P(\theta))
$$

with

$$
g(\lambda ; P) \equiv \lambda P[1-P]-\frac{[P 2 \lambda+V / 2]^{2} V^{2}}{16 \lambda^{2}(\lambda+V)},
$$

and $\theta=\underline{\theta}$ if $\tilde{\sigma}=\underline{\sigma}_{L}$, while $\theta=\bar{\theta}$ if $\widetilde{\sigma}=\bar{\sigma}_{H}$. Clearly, the function $g$ is increasing and unbounded in $\lambda$ for any given $P$, with $0<P<1$. Hence, there exists a critical cost parameter $\widehat{\lambda}_{1}$ such that $g(\lambda ; P)>0$ for all $\lambda>\widehat{\lambda}_{1}$.

(b) First, for $\boldsymbol{\mu}^{*}$ and $\sigma=\widehat{\sigma}$ the expected equilibrium profit of firm $S$ in (4.2) equals (using A.1, A.2 and B.1):

$$
\begin{aligned}
\Pi_{S}^{*}\left(\boldsymbol{\mu}^{*}(\widehat{\sigma}) ; \widehat{\sigma}\right) & =\Pi_{S}^{*}(\mathbf{0} ; \widehat{\sigma})=\frac{\lambda}{2} E\left\{x_{S}^{*}(\theta ; \varnothing)^{2}\right\}+\widehat{\sigma} V \widehat{X}(\widehat{\sigma}) \\
& =\frac{\lambda}{2} E\left\{\left(x_{R}^{*}(\theta)+\frac{[E(\theta)-\theta] V / 2}{\lambda(\lambda+V / 2)}\right)^{2}-x_{R}^{*}(\varnothing)^{2}\right\}+\Pi_{R}^{*}\left(\boldsymbol{\mu}^{*}(\widehat{\sigma}) ; \widehat{\sigma}\right) \\
& =\frac{\lambda}{2} E\left\{\left(x_{R}^{*}(\varnothing)+\frac{E(\theta)-\theta}{\lambda}\right)^{2}-x_{R}^{*}(\varnothing)^{2}\right\}+\Pi_{R}^{*}\left(\boldsymbol{\mu}^{*}(\widehat{\sigma}) ; \widehat{\sigma}\right) \\
& =\Pi_{R}^{*}\left(\boldsymbol{\mu}^{*}(\widehat{\sigma}) ; \widehat{\sigma}\right)+\frac{\lambda \cdot \operatorname{Var}(\theta)}{2 \lambda^{2}}
\end{aligned}
$$

Second, evaluating firm $S$ 's expected equilibrium profit at spillover level $\widetilde{\sigma} \in\left\{\underline{\sigma}_{L}, \bar{\sigma}_{H}\right\}$, i.e., full disclosure in equilibrium (using $x_{S}^{*}(\theta ; \theta)=x_{R}^{*}(\theta)$, as follows from A.2, and Lemma 1 d) yields immediately: $\Pi_{S}^{*}\left(\boldsymbol{\mu}^{*}(\widetilde{\sigma}) ; \widetilde{\sigma}\right)=\Pi_{R}^{*}\left(\boldsymbol{\mu}^{*}(\widetilde{\sigma}) ; \widetilde{\sigma}\right)$. Combining this ob- 
servation with (B.3) for some $\theta$ and (B.5) yields:

$$
\begin{aligned}
\sum_{i \in\{R, S\}} \Pi_{i}^{*}\left(\boldsymbol{\mu}^{*}(\widetilde{\sigma}) ; \widetilde{\sigma}\right) & =2 \Pi_{R}^{*}\left(\boldsymbol{\mu}^{*}(\widehat{\sigma}) ; \widehat{\sigma}\right)+2 g(P(\theta)) \frac{(\bar{\theta}-\underline{\theta})^{2}}{2(\lambda+V / 2)^{2}} \\
& =\sum_{i \in\{R, S\}} \Pi_{i}^{*}\left(\boldsymbol{\mu}^{*}(\widehat{\sigma}) ; \widehat{\sigma}\right)+g(P(\theta))\left(\frac{\bar{\theta}-\underline{\theta}}{\lambda+V / 2}\right)^{2}-\frac{\lambda \cdot \operatorname{Var}(\theta)}{2 \lambda^{2}} \\
& =\sum_{i \in\{R, S\}} \Pi_{i}^{*}\left(\boldsymbol{\mu}^{*}(\widehat{\sigma}) ; \widehat{\sigma}\right)+G(\lambda ; P(\theta)) \frac{(\bar{\theta}-\underline{\theta})^{2}}{2(\lambda+V / 2)^{2}}
\end{aligned}
$$

with

$$
G(\lambda ; P) \equiv P(1-P) \lambda \frac{\lambda^{2}-2 \lambda V / 2-(V / 2)^{2}}{\lambda^{2}}-\frac{[P 2 \lambda+V / 2]^{2} V^{2}}{16 \lambda^{2}(\lambda+V)},
$$

and $\theta=\underline{\theta}$ if $\widetilde{\sigma}=\underline{\sigma}_{L}$, while $\theta=\bar{\theta}$ if $\widetilde{\sigma}=\bar{\sigma}_{H}$. As in part (a), function $G$ is clearly increasing and unbounded in $\lambda$ for all $\lambda>\lambda^{*}$. Hence, there exists a critical cost parameter $\widehat{\lambda}_{2}>0$ such that $G(\lambda ; P)>0$ for all $\lambda>\widehat{\lambda}_{2}$. Proposition 9 implies that $\widehat{\lambda}_{2}>\lambda^{* *}$. Finally, define $\lambda^{* * *} \equiv \max \left\{\widehat{\lambda}_{1}, \widehat{\lambda}_{2}\right\}$, and the proof is complete.

Proposition 11 The expected probability of innovation in equilibrium, $I^{*}\left(\boldsymbol{\mu}^{*}(\sigma) ; \sigma\right)$, reaches the unique global maximum for $\sigma=0$.

Proof: The existence of the first local maximum at $\sigma=0$, and the absence of further local maxima on the interval $\left(0, \underline{\sigma}_{L}\right] \cup\left(\bar{\sigma}_{L}, \frac{1}{2}\right]$ follows immediately from monotonicity of $I^{*}\left(\boldsymbol{\mu}^{*}(\sigma) ; \sigma\right)$ on the interval, as implied by propositions 3 and 5 , and (5.3). Therefore, it suffices to show that $I^{*}(\mathbf{1} ; 0)>I^{*}\left(\mathbf{0} ; \underline{\sigma}_{L}\right)$, with $\underline{\sigma}_{L} \equiv s(0,1 ; \bar{\theta})$ and $s$ as in (A.17), to establish the global maximum can only be reached for $\sigma=0$. It is straightforward to show that:

$$
\begin{aligned}
I^{*}(\mathbf{1} ; 0) & =\widehat{X}(0)(2-\widehat{X}(0))-\frac{\operatorname{Var}(\theta)}{(\lambda+V / 2)^{2}} \\
I^{*}(\mathbf{0} ; \sigma) & =\widehat{X}(\sigma)(2-\widehat{X}(\sigma)) \\
& =\widehat{X}(0)(2-\widehat{X}(0))-\sigma \frac{V}{\lambda+V / 2}\left[2(1-\widehat{X}(0))+\sigma \frac{V}{\lambda+V / 2}\right]
\end{aligned}
$$

with $\operatorname{Var}(\theta)=p(1-p)(\bar{\theta}-\underline{\theta})^{2}$. Since $I^{*}(\mathbf{0} ; \sigma)$ is quadratic in $\sigma$, it is easy to find the spillover $\sigma_{0}$ such that $I^{*}\left(\mathbf{0} ; \sigma_{0}\right)=I^{*}(\mathbf{1} ; 0)$ :

$$
\sigma_{0} \equiv \frac{1}{V}\left(\sqrt{(\lambda+V / 2)^{2}(1-\widehat{X}(0))^{2}+\operatorname{Var}(\theta)}-(\lambda+V / 2)(1-\widehat{X}(0))\right)
$$


It is easy to verify that $\sigma_{0}$ is concave in $p$, and is maximized for $p=p_{0}$, with:

$$
p_{0} \equiv \frac{4 \lambda-2 V+3 \bar{\theta}+\underline{\theta}}{4(2 \lambda-V+\bar{\theta}+\underline{\theta})}
$$

Evaluating $\sigma_{0}$ at $p=p_{0}$ gives an upper bound for $\sigma_{0}$ :

$$
\sigma_{0} \leq \frac{(\bar{\theta}-\underline{\theta})^{2}}{4 V(2 \lambda-V+\bar{\theta}+\underline{\theta})}
$$

Using this upper bound and regularity condition (2.1) yields the following inequalities:

$$
\begin{aligned}
\underline{\sigma}_{L}-\sigma_{0} & \geq \frac{1}{2(\lambda+V)}\left(V-\bar{\theta}-\frac{(\bar{\theta}-\underline{\theta}) V / 2}{2 \lambda}\right)-\frac{(\bar{\theta}-\underline{\theta})^{2}}{4 V(2 \lambda-V+\bar{\theta}+\underline{\theta})} \\
& >\frac{1}{2(\lambda+V)}\left(V / 2-\frac{(V / 2-\underline{\theta}) V / 2}{2 \lambda}\right)-\frac{(V / 2-\underline{\theta})^{2}}{4 V(2 \lambda-V / 2+\underline{\theta})} \\
& \geq \frac{1}{2(\lambda+V)}\left(V / 2-\frac{(V / 2)^{2}}{2 \lambda}\right)-\frac{V / 2}{8(2 \lambda-V / 2)}=\frac{\left[14 \lambda^{2}-10 \lambda V+V^{2}\right] V / 2}{16 \lambda(\lambda+V)(2 \lambda-V / 2)}>0
\end{aligned}
$$

Monotonicity of $I^{*}(\mathbf{0} ; \sigma)$ in $\sigma$ (i.e. $\partial I^{*}(\mathbf{0} ; \sigma) / \partial \sigma<0$ as Proposition 5 shows) yields immediately: $I^{*}(\mathbf{1} ; 0)=I^{*}\left(\mathbf{0} ; \sigma_{0}\right)>I^{*}\left(\mathbf{0} ; \underline{\sigma}_{L}\right) \geq I^{*}(\mathbf{0} ; \sigma)$ for any $\sigma \in\left[\underline{\sigma}_{L}, \bar{\sigma}_{L}\right]$. Moreover, monotonicity of $I^{*}(\mu ; \sigma)$ in $\mu(\bar{\theta})$ (i.e. $\partial I^{*}(\boldsymbol{\mu} ; \sigma) / \partial \mu(\bar{\theta})<0$ as proposition 5 shows) implies that $I^{*}(\mathbf{0} ; \sigma) \geq I^{*}\left(0, \mu^{L}(\sigma) ; \sigma\right)=I^{*}\left(\boldsymbol{\mu}^{*}(\sigma) ; \sigma\right)$ for any $\sigma \in\left[\underline{\sigma}_{L}, \bar{\sigma}_{L}\right]$. 


\section{References}

Anton, J.J. and Yao, D.A., 2003, 'Patents, Invalidity, and the Strategic Transmission of Enabling Information,' Journal of Economics and Management Strategy 12, pp. 151-178.

Anton, J.J. and Yao, D.A., 2004, 'Little Patents and Big Secrets: Managing Intellectual Property,' RAND Journal of Economics 35, pp. 1-22.

d'Aspremont, C.; Bhattacharya, S. and Gérard-Varet, L-A., 1998, 'Knowledge as a Public Good: Efficient Sharing and Incentives for Development Effort,' Journal of Mathematical of Economics 30, pp. 389-404.

d'Aspremont, C.; Bhattacharya, S. and Gérard-Varet, L-A., 2000, 'Bargaining and Sharing Innovative Knowledge,' Review of Economic Studies 67, pp. 255-271.

Austen, D.H., 1993, 'An Event-Study Approach to Measuring Innovative Output: The Case of Biotechnology,' American Economic Review (Papers and Proceedings) 83, pp. 253-258.

Bhattacharya, S.; Glazer, J. and Sappington, D.E.M., 1990, 'Sharing Productive Knowledge in Internally Finance R\&D Contests,' Journal of Industrial Economics 39, pp. 187-208.

Bhattacharya, S.; Glazer, J. and Sappington, D.E.M., 1992, 'Licensing and the Sharing of Knowledge in Research Joint Ventures,' Journal of Economic Theory 56, pp. 43-69.

Bhattacharya, S. and Guriev, S., 2006, 'Patents vs. Trade Secrets: Knowledge Licensing and Spillover,' Journal of the European Economic Association 4, pp. 1112-1147.

Bhattacharya, S. and Ritter, J.R., 1983, 'Innovation and Communication: Signalling with Partial Disclosure,' Review of Economic Studies 50, pp. 331-346.

Choi, J.P., 1991 'Dynamic R\&D Competition under 'Hazard Rate' Uncertainty,' RAND Journal of Economics 22, pp. 596-610.

De Fraja, G., 1993, 'Strategic Spillovers in Patent Races,' International Journal of Industrial Organization 11, pp. 139-146.

Denicolò V., 1996, 'Patent Races and Optimal Patent Breadth and Length,' Journal of Industrial Economics 44, pp. 249-265. 
Dye, R.A., 1985, 'Disclosure of Nonproprietary Information,' Journal of Accounting Research 23, pp. 123-145.

Farrell, J., 1986, 'Voluntary Disclosure: Robustness of the Unraveling Result, and Comments on Its Importance,' in Grieson, R. (ed.), Antitrust and Regulation (Lexington Books, Lexington).

Fosfuri, A. and Rønde, T., (2004) 'High-Tech Clusters, Technology Spillovers, and Trade Secret Laws,' International Journal of Industrial Organization 22, pp. 45-65.

Gersbach, H. and Schmutzler, A., 2003, 'Endogenous Technological Spillovers: Causes and Consequences,' Journal of Economics and Management Strategy 12, pp. 197-205.

Gill, D., 2008 'Strategic Disclosure of Intermediate Research Results,' Journal of Economics and Management Strategy, 17, pp. 733-758.

Grossman, S.J., 1981, 'The Informational Role of Warranties and Private Disclosure about Product Quality,' Journal of Law and Economics 24, pp. 461-483.

Hendricks, K. and Kovenock, D., 1989, 'Asymmetric Information, Information Externalities, and Efficiency: The Case of Oil Exploration,' RAND Journal of Economics 20, pp. 164-182.

Jansen, J., 2001, 'Strategic Information Revelation and Revenue Sharing in an R\&D Race,' Discussion Paper FS IV 01-06, Social Science Research Center Berlin (WZB).

Jansen, J., 2004, 'Strategic Information Revelation in an R\&D Race with Spillovers,' mimeo, Social Science Research Center Berlin (WZB), http://ssrn.com/abstract=517982.

Jansen, J., 2008, 'Information Acquisition and Strategic Disclosure in Oligopoly,' Journal of Economics and Management Strategy 17, pp. 113-148.

Kamien, M.I. and Zang, I., 2000, 'Meet Me Halfway: Research Joint Ventures and Absorptive Capacity,' International Journal of Industrial Organization 18, pp. 9951012.

Katsoulacos, Y. and Ulph, D., 1998, 'Endogenous Spillovers and the Performance of Research Joint Ventures,' Journal of Industrial Economics 46, pp. 333-357.

Kirby, A.J., 1988, 'Trade Associations as Information Exchange Mechanisms,' RAND Journal of Economics 19, pp. 138-146. 
Lewis, T.R. and Sappington, D.E.M., 1989, 'Countervailing Incentives in Agency Problems,' Journal of Economic Theory 49, pp. 294-313.

Milgrom, P.R., 1981, 'Good News and Bad News: Representation Theorems and Applications,' Bell Journal of Economics 12, pp. 380-391.

Moldovanu, B. and Sela, A., 2001, 'The Optimal Allocation of Prizes in Contests,' American Economic Review 91, pp. 542-558.

Okuno-Fujiwara, M.; Postlewaite, A. and Suzumura, K., 1990, 'Strategic Information Revelation,' Review of Economic Studies 57, pp. 25-47.

Raith, M., 1996 'A General Model of Information Sharing in Oligopoly,' Journal of Economic Theory 71, pp. 260-288.

Rosenkranz, S., 2001, 'To Reveal or Not to Reveal: Know-How Disclosure and Joint Ventures in Procurement Auctions,' Journal of Institutional and Theoretical Economics 157, pp. 555-567.

Shin, H.S., 1994, 'News Management and the Value of Firms,' RAND Journal of Economics 25, pp. 58-71.

Vives, X., 1984, 'Duopoly Information Equilibrium: Cournot and Bertrand", Journal of Economic Theory 34, pp. 71-94.

Vives, X., 1999, Oligopoly Pricing: Old Ideas and New Tools, (MIT Press, Cambridge). Ziv, A., 1993, 'Information Sharing in Oligopoly: The Truth-telling Problem,' RAND Journal of Economics 24, pp. 455-465. 


\section{Preprints 2009}

Niels Petersen: Abkehr von der internationalen Gemeinschaft? - Die aktuelle Rechtsprechung des US Supreme Court zur innerstaatlichen Wirkung von völkerrechtlichen Verträgen. 2009/5.

Johannes Rincke / Christian Traxler: Deterrence Through Word of Mouth. 2009/4.

Christian Traxler / Joachim Winter: Survey Evidence on Conditional Norm Enforcement. 2009/3.

Britta Herbig / Andreas Glöckner: Experts and Decision Making: First Steps Towards a Unifying Theory of Decision Making in Novices, Intermediates and Experts. 2009/2.

Martin Beckenkamp: Environmental dilemmas revisited: structural consequences from the angle of institutional ergonomics. $2009 / 1$.

\section{Preprints 2008}

Carsten Burhop: The Underpricing of Initial Public Offerings in Imperial Germany, 1870-1896. 2008/46.

Martin Hellwig: A Note on Deaton's Theorem on the Undesirability of Nonuniform Excise Taxation. 2008/45.

Martin Hellwig: Zur Problematik staatlicher Beschränkungen der Beteiligung und der Einflussnahme von Investoren bei großen Unternehmen. 2008/44.

published in: Zeitschrift für das gesamte Handelsrecht und Wirtschaftsrecht 172 (2008), 768 - 787

Martin Hellwig: Systemic Risk in the Financial Sector: An Analysis of the Subprime-Mortgage Financial Crisis. 2008/43.

Andreas Glöckner / Ann-Katrin Herbold: Information Processing in Decisions under Risk: Evidence for Compensatory Strategies based on Automatic Processes. 2008/42.

Jörn Lüdemann / Stefan Magen: Effizienz statt Gerechtigkeit? 2008/41.

Christoph Engel: Die Bedeutung der Verhaltensökonomie für das Kartellrecht. 2008/40.

Felix Bierbrauer: A unified approach to the revelation of public goods preferences and to optimal income taxation. 2008/39.

Carsten Burhop / Thorsten Lübbers: Incentives and Innovation? R\&D Management in Germany’s High-Tech Industries During the Second Industrial Revolution. 2008/38.

Andreas Nicklisch / Tobias Salz: Reciprocity and status in a virtual field experiment. 2008/37.

Andreas Glöckner / Christoph Engel: Can We Trust Intuitive Jurors? An Experimental Analysis. 2008/36.

Jörn Lüdemann: Wettbewerb und Regulierung in der Telekommunikation. Das Telekommunikationsrecht vor den Herausforderungen dynamischer Märkte. 2008/35.

published in: Jörn Lüdemann (Hrsg.), Telekommunikation, Energie, Eisenbahn - Welche Regulierung brauchen die Netzwirtschaften? Tübingen (Mohr Siebeck) 2008, S. 69-99

Martin Beckenkamp: Playing strategically against nature? - Decisions viewed from a game-theoretic frame. 2008/34.

Christoph Engel: Preponderance of the Evidence versus Intime Conviction. A Behavioural Perspective on a Conflict between American and Continental European Law? 2008/33.

Kristoffel Grechenig: Schadenersatz bei Verletzung von $§ 14 \mathrm{WpHG}$ ? Insiderhandel mit positiver und negativer Information. 2008/32.

Felix Bierbrauer: Optimal Income Taxation, Public Goods Provision and Robust Mechanism Design. 2008/31.

Hans-Theo Normann: Vertical Integration, Raising Rivals' Costs and Upstream Collusion. 2008/30.

forthcoming in: European Economic Review 
Martin Hellwig: Competition Policy and Sector-Specific Regulation for Network Industries. 2008/29.

forthcoming in: X. Vives (ed.), "Competition Policy in the EU: Fifty Years on from the Treaty of Rome" Oxford University Press.

Niels Petersen: Rational Choice or Deliberation? - Customary International Law between Coordination and Constitutionalization. 2008/28.

forthcoming in: Journal of Institutional and Theoretical Economics 165 (2009)

Stephen Broadberry / Carsten Burhop: Resolving the Anglo-German Industrial Productivity Puzzle, 1895-1935:

A Response to Professor Ritschl. 2008/27.

forthcoming in: Journal of Economic History

Niels Petersen: Demokratie und Grundgesetz - Veränderungen des Demokratieprinzips in Art. 20 Abs. 2 GG angesichts der Herausforderungen moderner Staatlichkeit. 2008/26.

forthcoming: Jahrbuch des öffentlichen Rechts der Gegenwart 57 (2009)

Andreas Nicklisch: Semi-collusive advertising and pricing in experimental duopolies. 2008/25.

Andreas Nicklisch: Inequity Aversion, Reciprocity, and Appropriateness in the Ultimatum-Revenge Game. 2008/24.

Christoph Engel: The Behaviour of Corporate Actors. A Survey of the Empirical Literature. 2008/23.

Emanuel Vahid Towfigh: Komplexität und Normenklarheit - oder: Gesetze sind für Juristen gemacht. 2008/22.

Christian Traxler / Andreas Reutter: Apportionment, Fiscal Equalization and Decentralized Tax Enforcement. 2008/21.

Christoph Engel, REITs ante portas. Die Anpassung des deutschen Rechts an institutionelle Investoren in den Grundstücks- und Mietmärkten. 2008/20.

forthcoming in: Juristenzeitung

Christoph Engel, Ernst-Joachim Mestmäcker. 2008/19.

forthcoming in: Stefan Grundmann / Karl Riesenhuber (eds.): Deutschsprachige Zivilrechtslehrer des 20. Jahrhunderts in Berichten ihrer Schüler, Band 2, Berlin (De Gruyter)

Andreas Glöckner, „Neurorecht“ ohne Psychologie? Die Rolle verhaltenswissenschaftlicher Betrachtungsebenen bei der Ableitung rechtspolitischer Empfehlungen. 2008/18.

forthcoming in: S. Schleim, T. M. Spranger \& H. Walter (Eds.), Von der Neuroethik zum Neurorecht? Göttingen: Vandenhoeck \& Ruprecht.

Ernesto Crivelli/Klaas Staal, Size, Spillovers and Soft Budget Constraints. 2008/17.

Niels Petersen, The Principle of Democratic Teleology in International Law. 2008/16.

Markus Quirin/Martin Beckenkamp/Julius Kuhl, Giving or Taking: The Role of Dispositional Power Motivation and Positive Affect in Profit Maximization. 2008/15.

Andreas Glöckner/Tilmann Betsch/Nicola Schindler, Construction of Probabilistic Inferences by Constraint Satisfaction. 2008/14.

Carsten Burhop/Thorsten Lübbers, Cartels, managerial incentives, and productive efficiency in German coal mining, 1881-1913. 2008/13. 